\title{
Acid-Induced Liberation of Polysubstituted Cyclopentadiene Ligands from Cyclopentadienyl Cobalt: A [2 + 2+1] Cycloaddition Route Toward 1,2,4-Trisubstituted Cyclopentadienes
}

Pengjin Qin, ${ }^{\dagger}$ Ryan L. Holland, ${ }^{\dagger}$ Kevin D. Bunker, ${ }^{\dagger}$ Joseph M. O’Connor, ${ }^{* \dagger}$ Kim K. Baldridge, ${ }^{*}$ and Arnold L. Rheingold ${ }^{\dagger}$

'Department of Chemistry, University of California, San Diego, La Jolla, California 92093, and `School of Pharmaceutical Science and Technology, Tianjin University, 92 Weijin Road, Nankai District, Tianjin, P. R. of China.

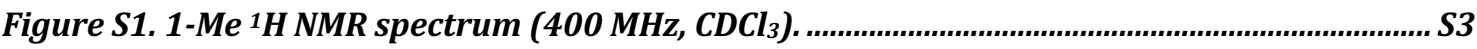

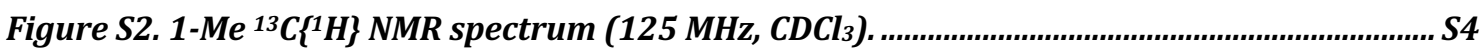

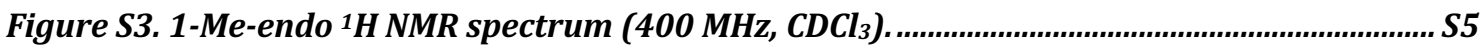

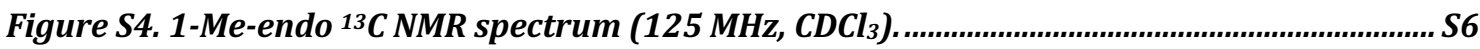

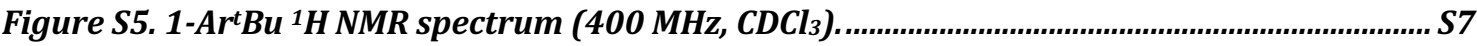

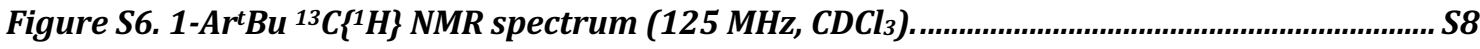

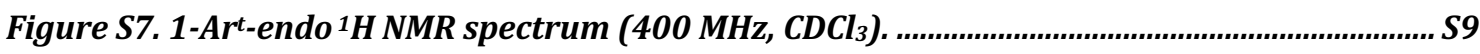

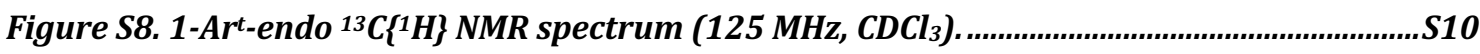

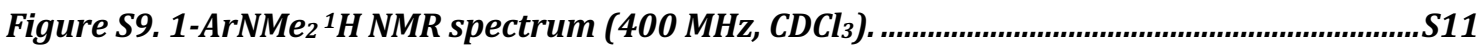

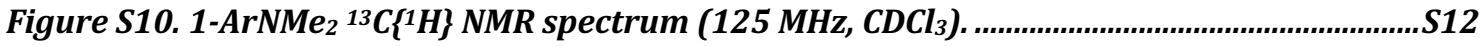

Figure S11. 8-Me-A and 8-Me-B ${ }^{1} \mathrm{H} N M R$ spectrum (400 $\left.\mathrm{MHz}, \mathrm{CDCl}_{3}\right)$.........................................

Figure S12. 8-Me-A and 8-Me-B $\left.{ }^{13} C^{1}{ }^{1} \mathrm{H}\right\}$ NMR spectrum $\left(125 \mathrm{MHz}, \mathrm{CDCl}_{3}\right)$.................................

Figure S13. 8-Ph-A and 8-Ph-B ${ }^{1} \mathrm{H}$ NMR spectrum (400 MHz, $\left.\mathrm{CDCl}_{3}\right)$. ...........................................

Figure S14. 8-Ph-A and 8-Ph-B $\left.{ }^{13} C^{1}{ }^{1} \mathrm{H}\right\}$ NMR spectrum (125 MHz, $\left.\mathrm{CDCl}_{3}\right)$.....................................

Figure S15. 8-ArtBu-A and 8-ArtBu-B ${ }^{1} \mathrm{H} N M R$ spectrum (400 $\left.\mathrm{MHz}, \mathrm{CDCl}_{3}\right)$.................................

Figure S16. 8-Art Bu-A and 8-ArtBu-B $\left.{ }^{13} C^{1}{ }^{1} \mathrm{H}\right\}$ NMR spectrum (125 $\left.\left.\mathrm{MHz}, \mathrm{CDCl}_{3}\right)\right)$........................S18

Figure S17. 8-ArNMe $e_{2}-\mathrm{A}$ and 8-ArNMe $2-\mathrm{B}^{1} \mathrm{H} \mathrm{NMR}$ spectrum (400 MHz, $\left.\mathrm{CDCl}_{3}\right)$...........................

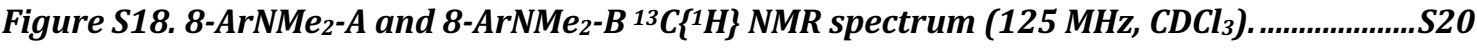

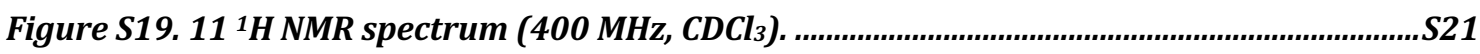

Figure S20. $\left.11{ }^{13} \mathrm{C}_{\{1} \mathrm{H}\right\}$ NMR spectrum $\left(125 \mathrm{MHz}, \mathrm{CDCl}_{3}\right)$. 


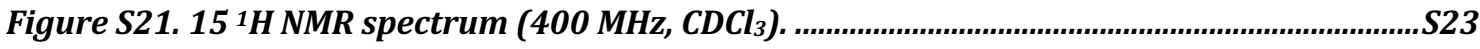

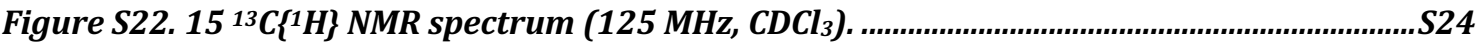

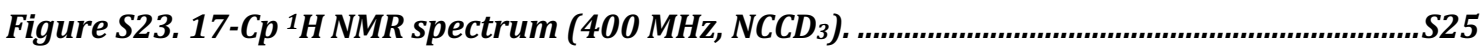

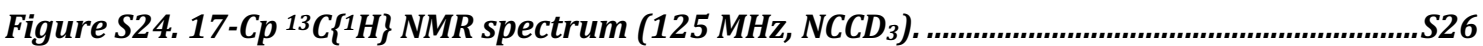

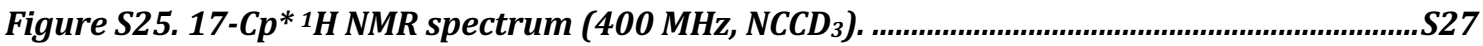

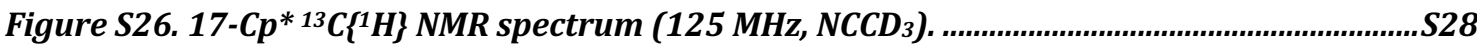

Figure S27. ORTEP of 8-Ph-A/8-Ph-B. Thermal ellipsoids shown at 30\% probability. Most hydrogen atoms are omitted for clarity. The sample was prepared from recrystalliazation in

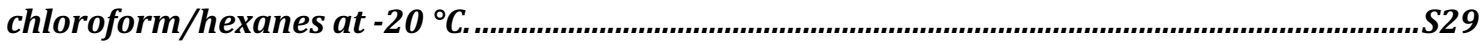

Table S1. Crystal data and structure refinement for 8-Ph-A/8-Ph-B.......................................S29

Figure S28. ORTEP of 8-CO $\mathrm{CO}_{2}$ Me. Thermal ellipsoids shown at 30\% probability. Most hydrogen atoms are omitted for clarity. The sample was prepared from recrystalliazation in $\mathrm{CH}_{2} \mathrm{Cl}_{2} /$ hexanes S30

Table S2. Crystal data and structure refinement for 8- $\mathrm{CO}_{2} \mathrm{Me}$. .530

Figure S29. ORTEP of 9. Thermal ellipsoids shown at $30 \%$ probability. The sample was prepared from crystalliazation of the crude oil in the presence of small amount of chloroform overnight $S 31$

Table S3. Crystal data and structure refinement for 9. .531

Figure S30. ORTEP of 11. Thermal ellipsoids shown at 30\% probability. Most hydrogen atoms are omitted for clarity. The sample was prepared from recrystalliazation in chloroform/hexanes at $-20^{\circ} \mathrm{C}$ S32

Table S4. Crystal data and structure refinement for 11. .532

Figure S31. ORTEP of 15. Thermal ellipsoids shown at 30\% probability. Most hydrogen atoms are omitted for clarity. The sample was prepared from recrystalliazation in chloroform/hexanes. S33

Table S5. Crystal data and structure refinement for 15. .533

Figure S32. ORTEP of 17-Cp*. Thermal ellipsoids shown at 30\% probability. Most hydrogen atoms are omitted for clarity. The sample was prepared from recrystalliazation in toluenes/hexanes at $-20^{\circ} \mathrm{C}$.

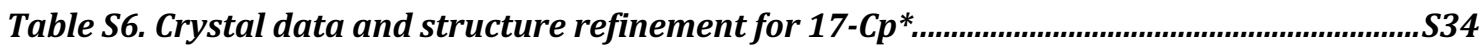

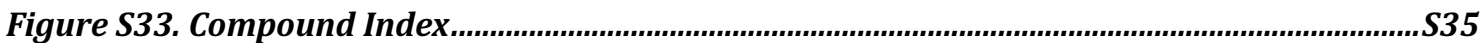

Table S7. Computational results, Z-matrices or Cartesian coordinates, the number of imaginary frequencies, and computed total energies. 


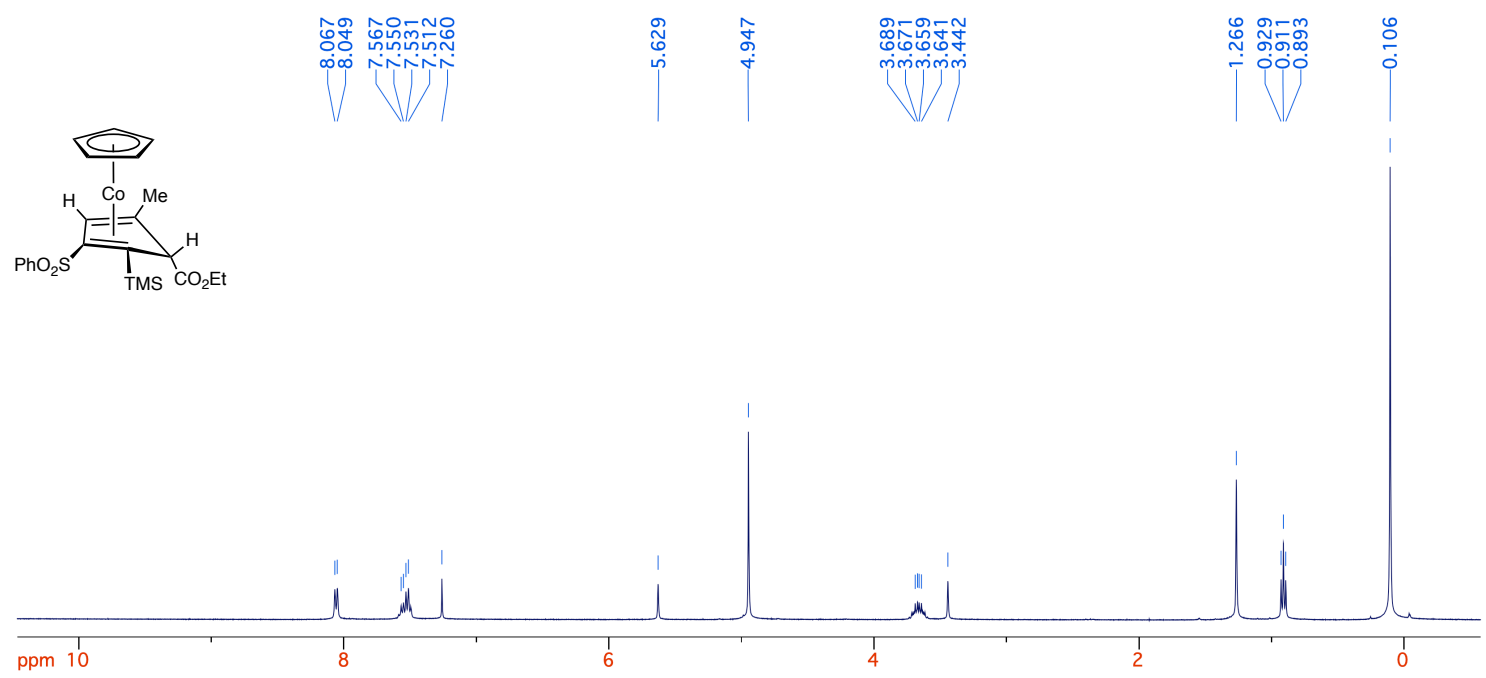

Figure S1. 1-Me ${ }^{1} \mathrm{H}$ NMR spectrum (400 MHz, $\left.\mathrm{CDCl}_{3}\right)$. 


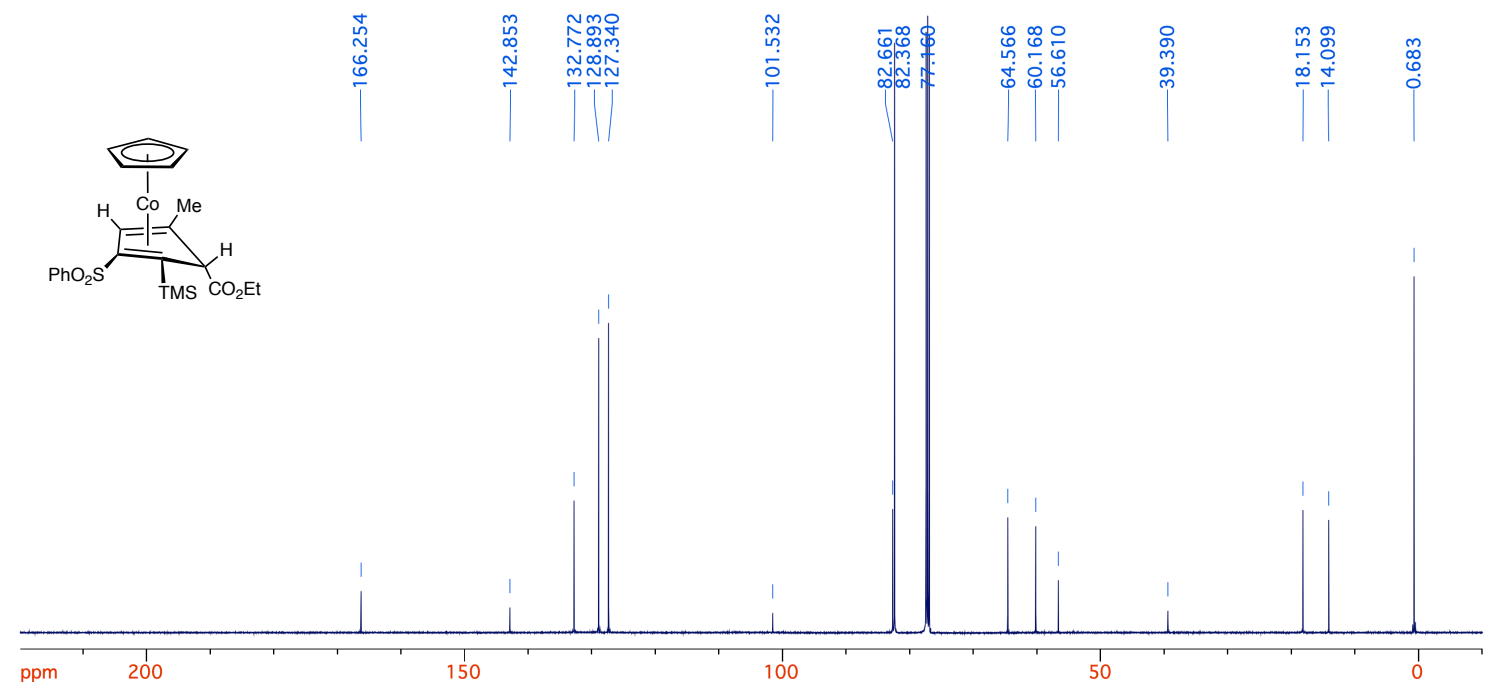

Figure S2. 1-Me ${ }^{13} \mathrm{C}\left\{{ }^{1} \mathrm{H}\right\}$ NMR spectrum (125 $\left.\mathrm{MHz}, \mathrm{CDCl}_{3}\right)$. 


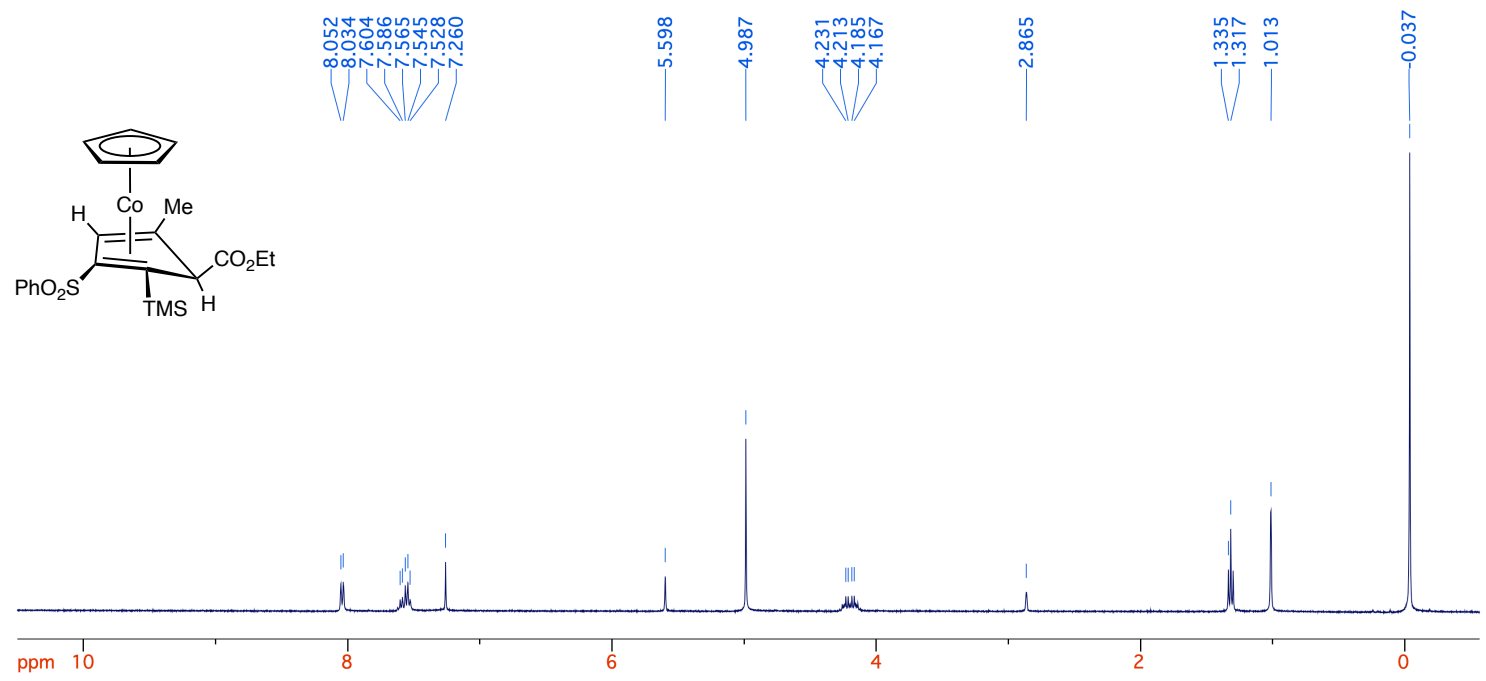

Figure S3. 1-Me-endo ${ }^{1} \mathrm{H}$ NMR spectrum $\left(400 \mathrm{MHz}, \mathrm{CDCl}_{3}\right)$. 


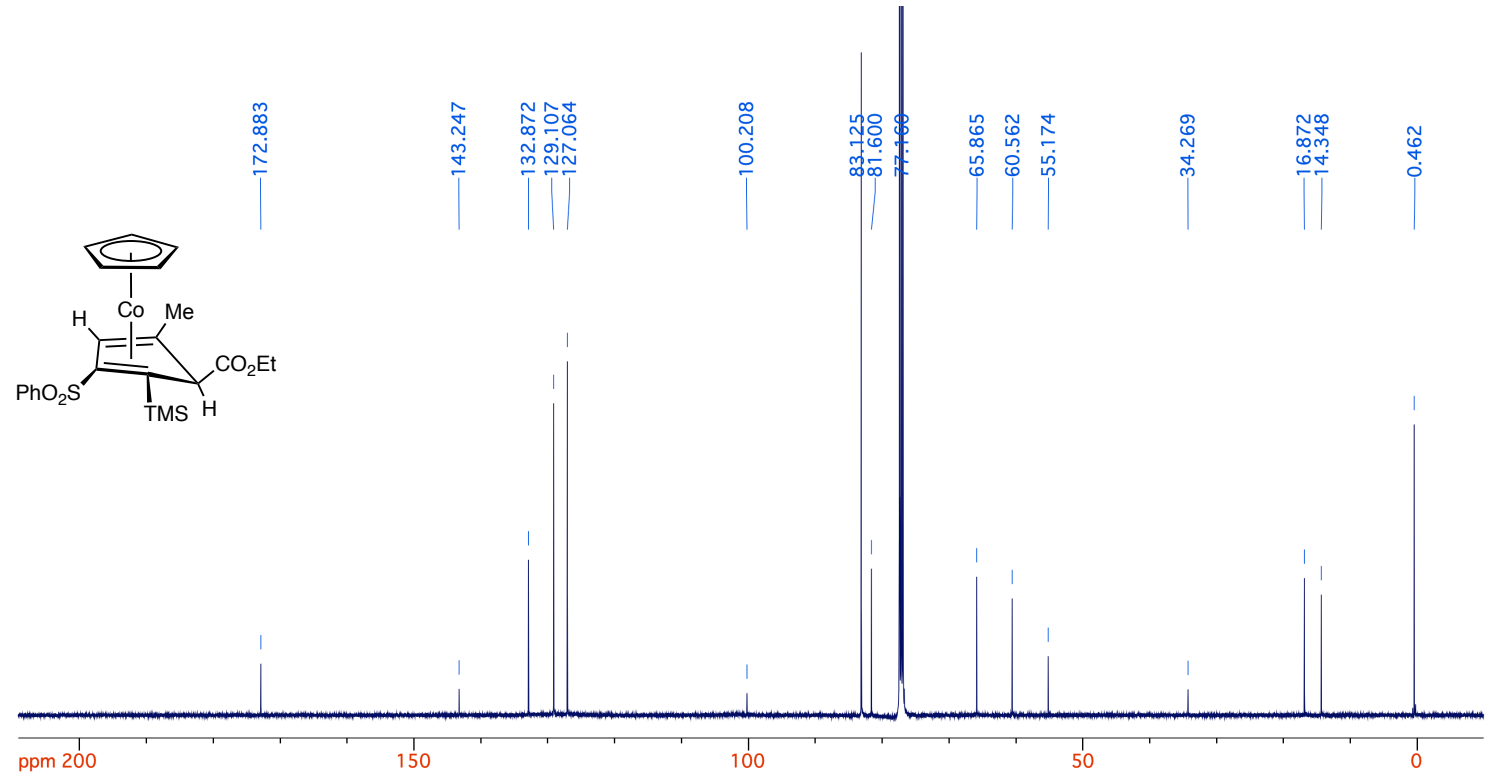

Figure S4. 1-Me-endo ${ }^{13} \mathrm{C}$ NMR spectrum (125 MHz, $\left.\mathrm{CDCl}_{3}\right)$. 


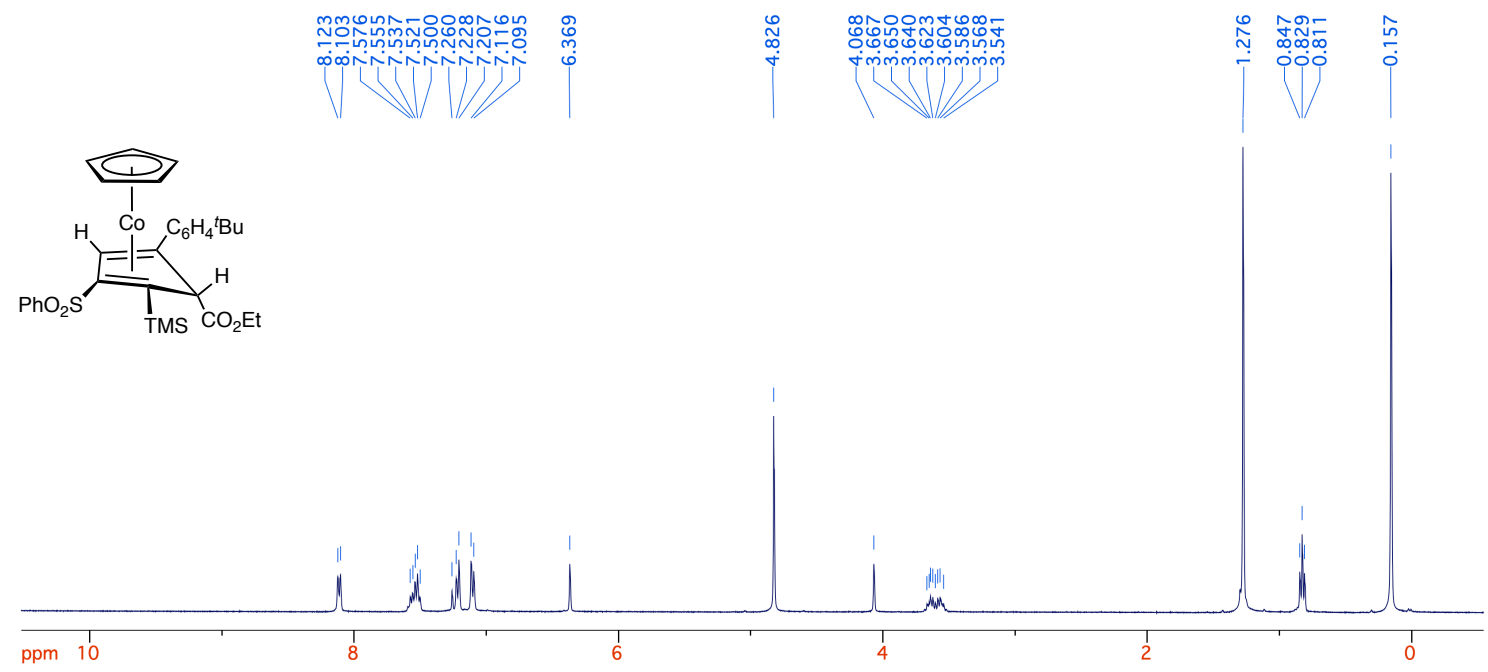

Figure S5. 1- $A r^{t} B u^{1} \mathrm{H}$ NMR spectrum (400 $\left.\mathrm{MHz}, \mathrm{CDCl}_{3}\right)$. 


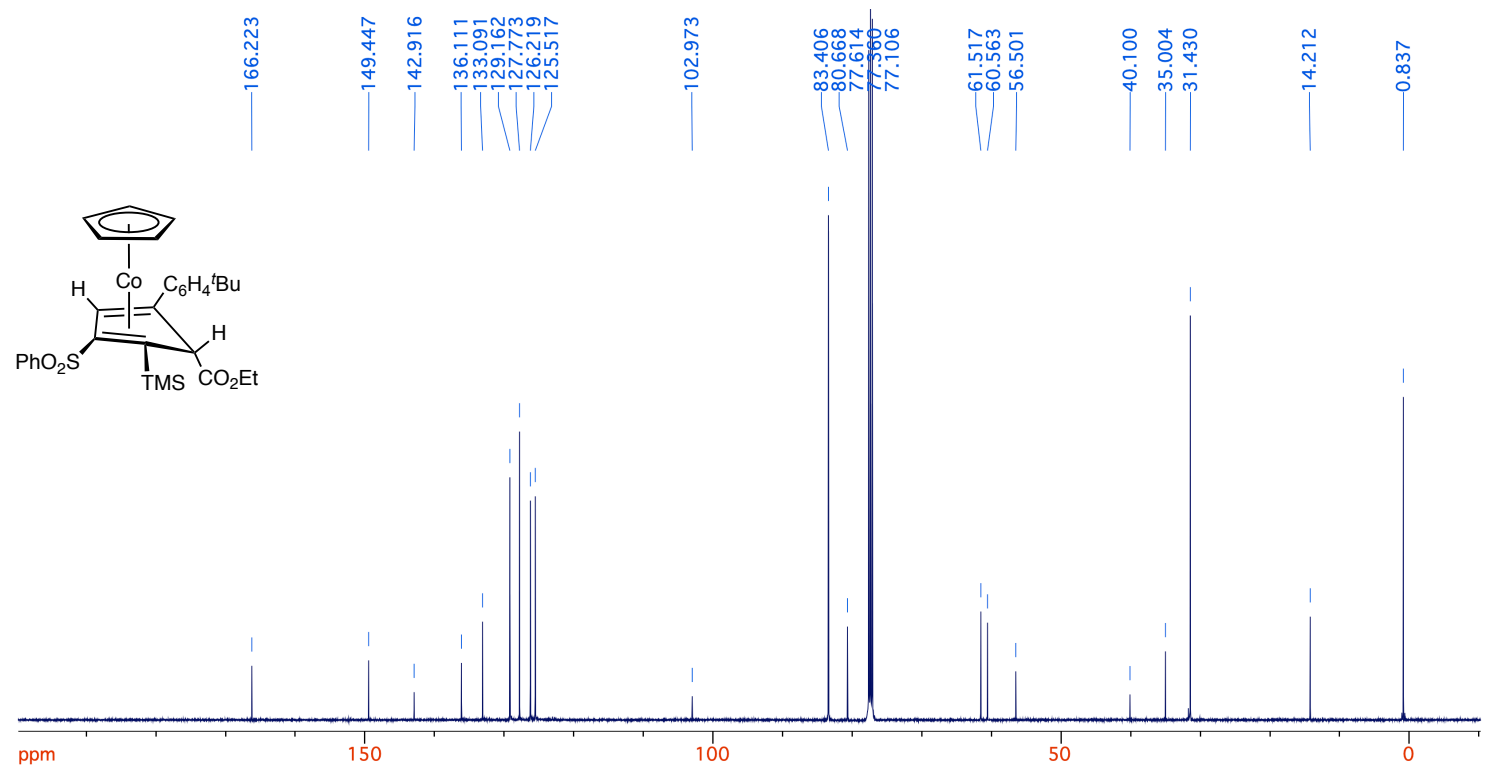

Figure S6. 1- $A r^{t} B u{ }^{13} \mathrm{C}\left\{{ }^{1} \mathrm{H}\right\}$ NMR spectrum (125 MHz, $\left.\mathrm{CDCl}_{3}\right)$. 


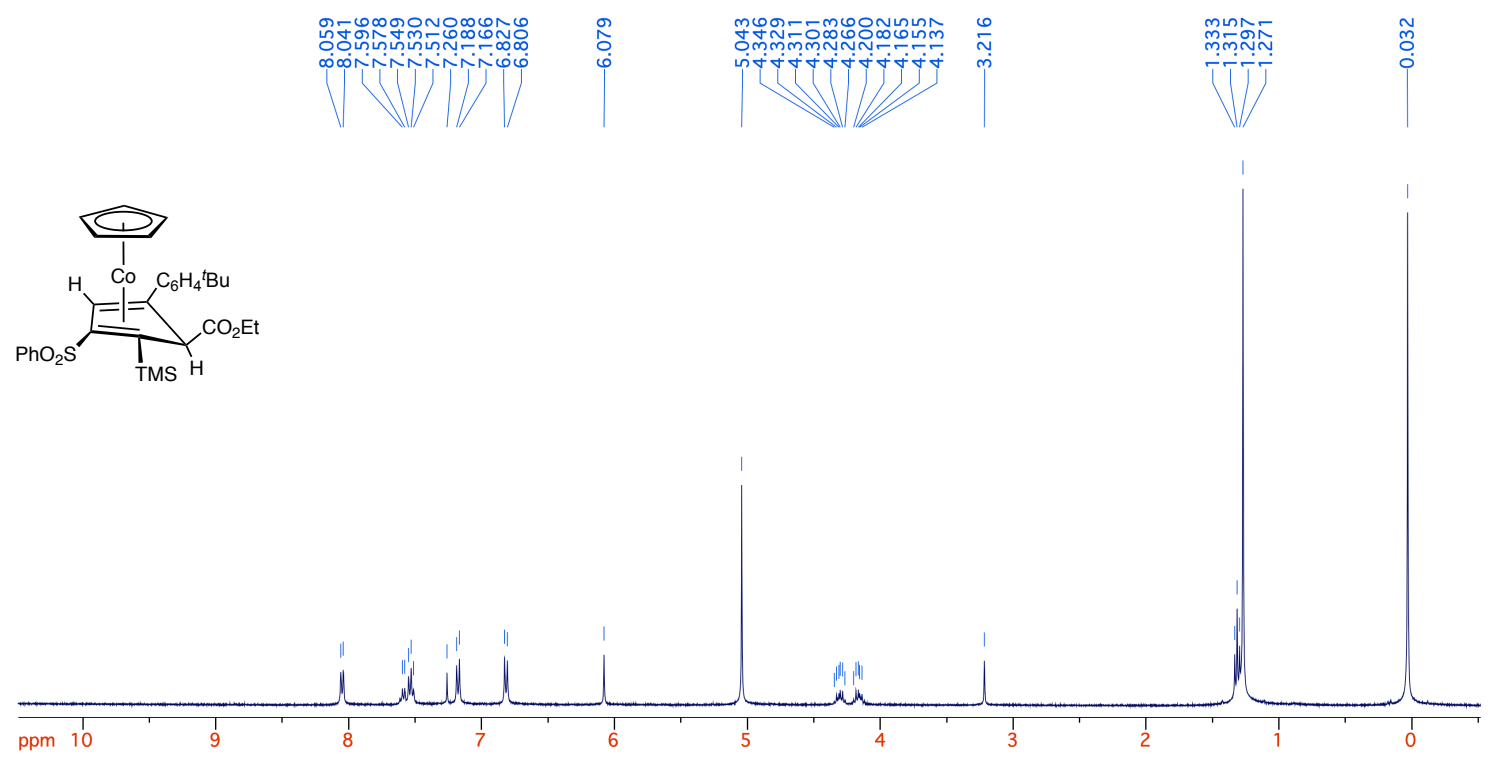

Figure S7. 1-Ar $r^{t}$-endo ${ }^{1} \mathrm{H}$ NMR spectrum (400 $\left.\mathrm{MHz}, \mathrm{CDCl}_{3}\right)$. 


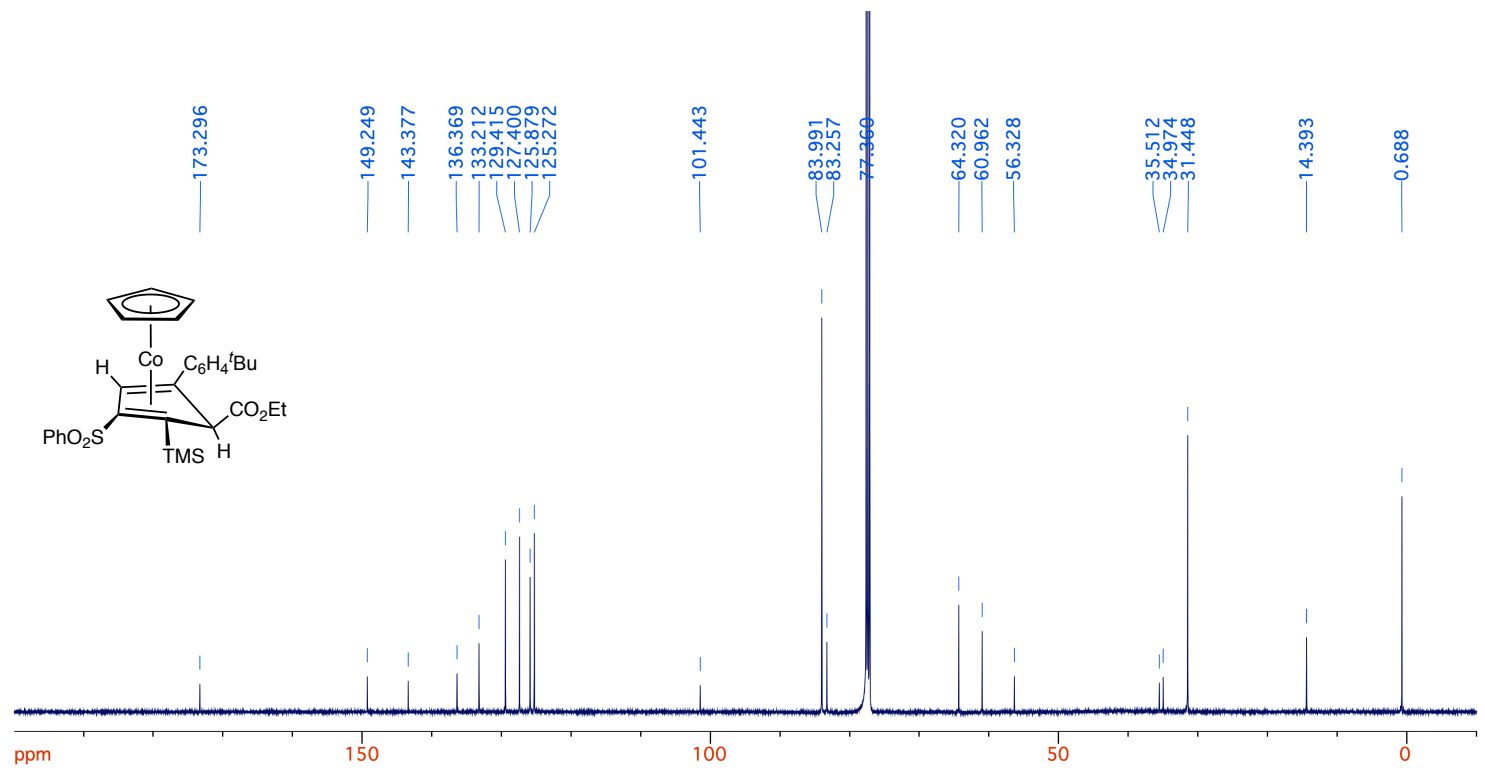

Figure S8. 1-Ar $r^{t}$-endo ${ }^{13} \mathrm{C}\left\{{ }^{1} \mathrm{H}\right\}$ NMR spectrum $\left(125 \mathrm{MHz}, \mathrm{CDCl}_{3}\right)$. 


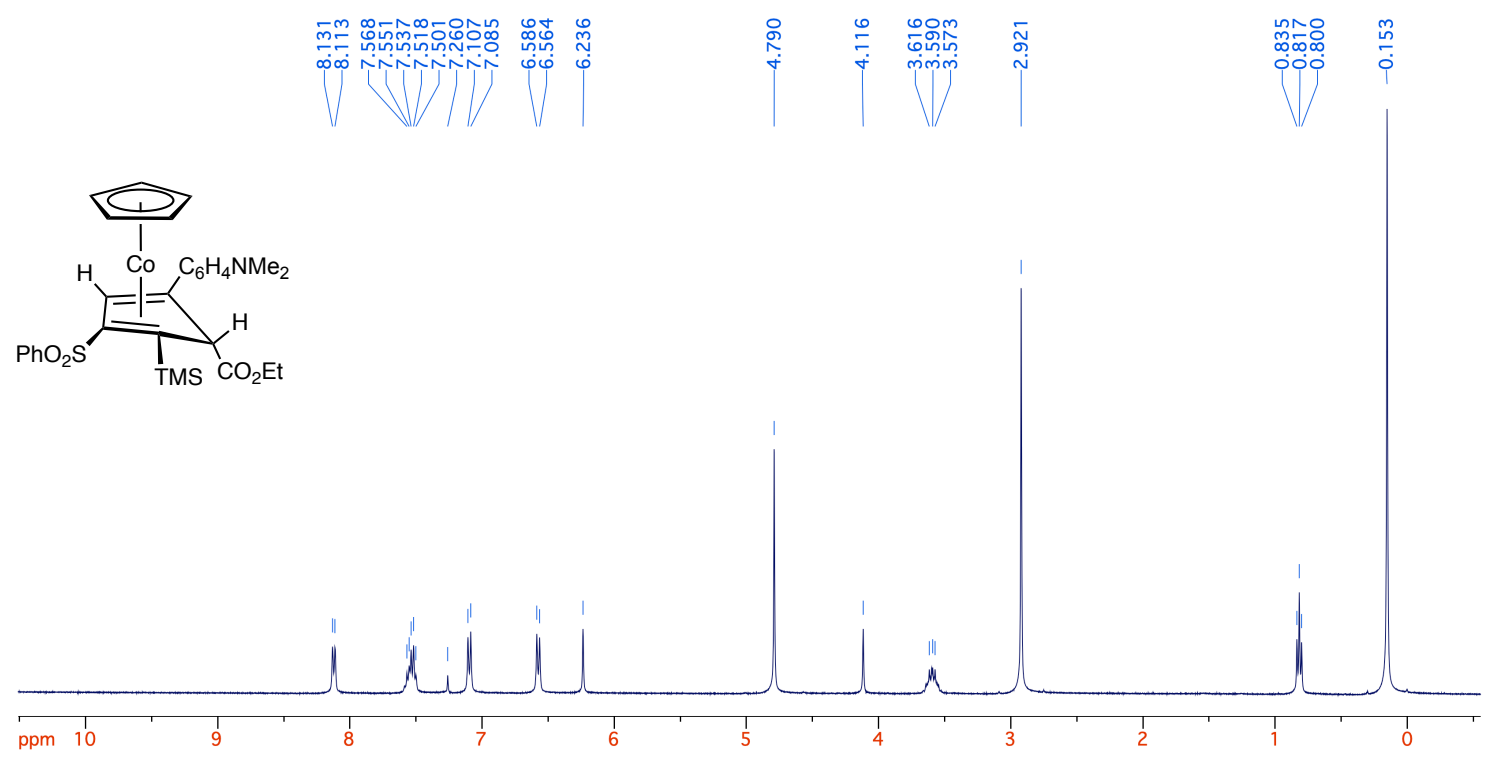

Figure S9. 1- $\mathrm{ArNMe}_{2}{ }^{1} \mathrm{H}$ NMR spectrum (400 $\left.\mathrm{MHz}, \mathrm{CDCl}_{3}\right)$. 


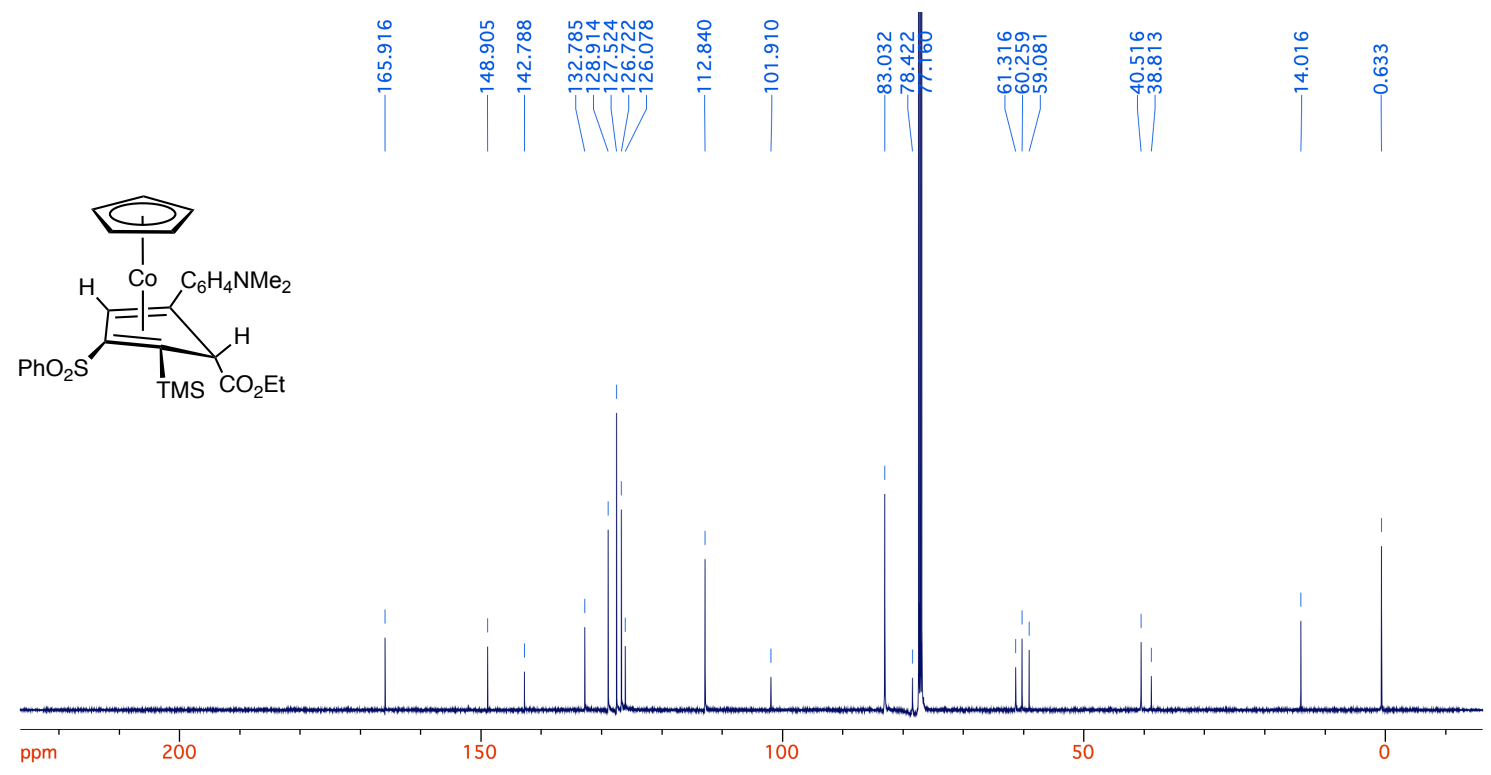

Figure S10. 1-ArNMe ${ }_{2}^{13} \mathrm{C}\left\{{ }^{1} \mathrm{H}\right\}$ NMR spectrum (125 MHz, $\left.\mathrm{CDCl}_{3}\right)$. 


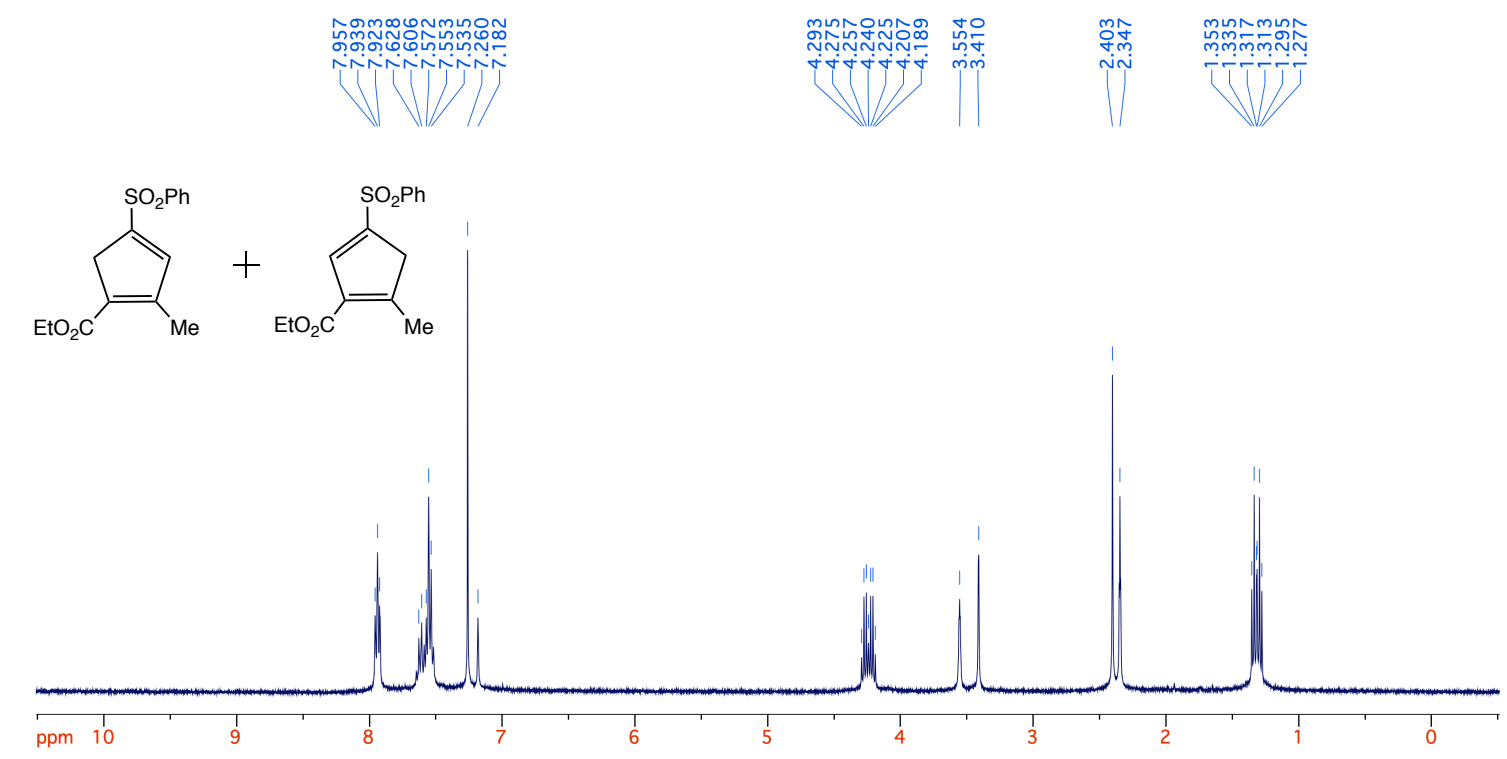

Figure S11. 8-Me- $A$ and 8-Me- $B{ }^{1} \mathrm{H}$ NMR spectrum (400 $\left.\mathrm{MHz}, \mathrm{CDCl}_{3}\right)$. 


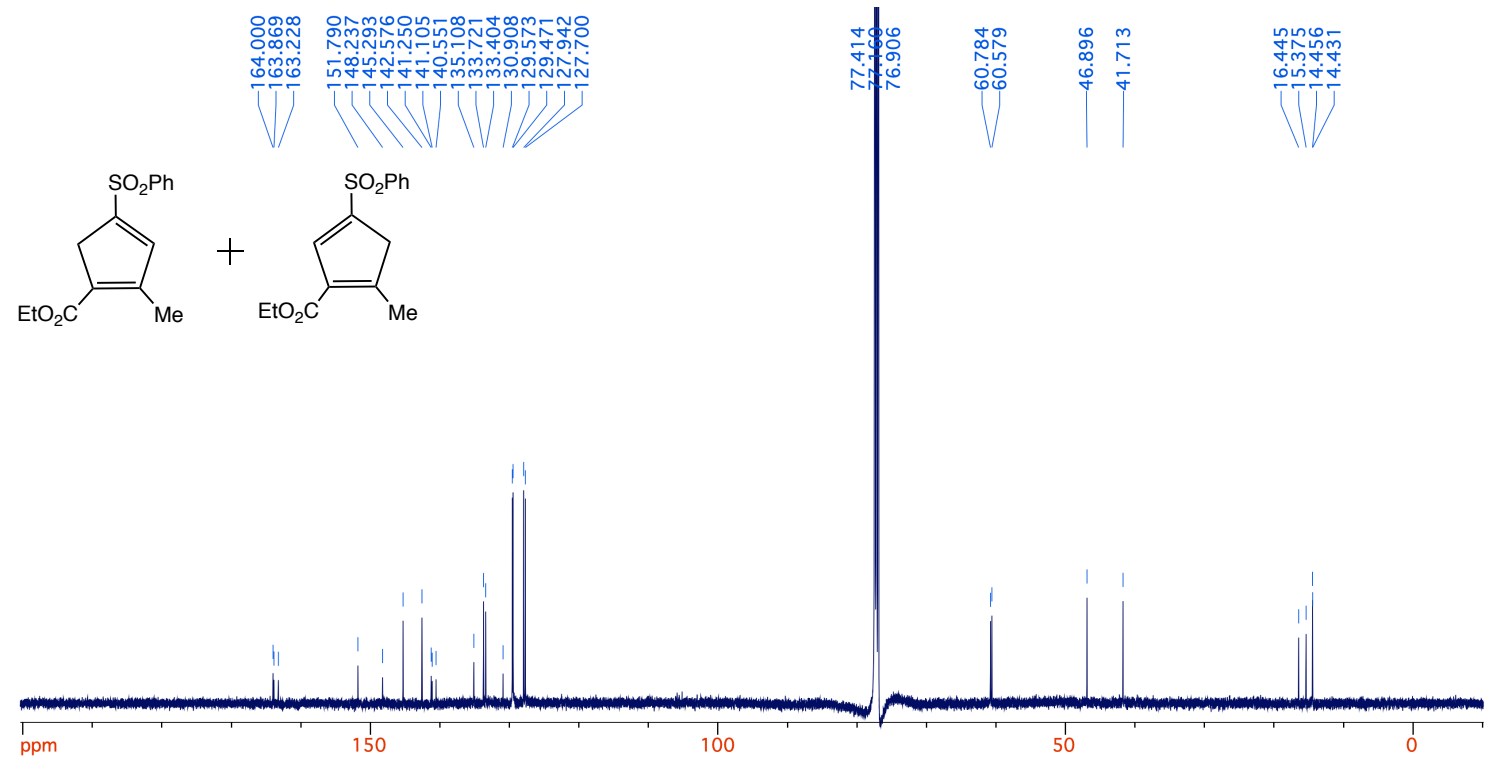

Figure S12. 8-Me- $A$ and 8-Me-B ${ }^{13} \mathrm{C}\left\{{ }^{1} \mathrm{H}\right\}$ NMR spectrum (125 $\left.\mathrm{MHz}, \mathrm{CDCl}_{3}\right)$. 


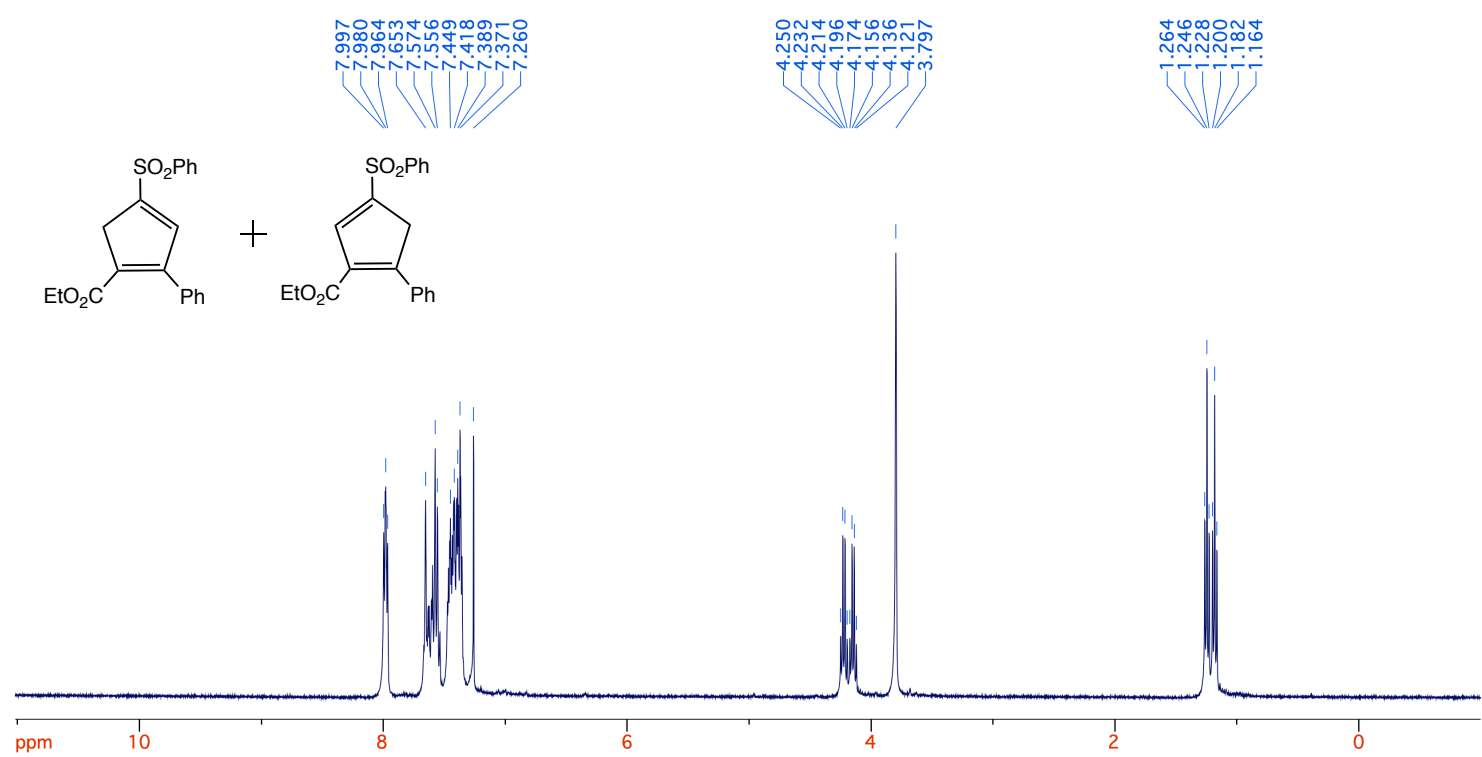

Figure S13. 8-Ph- $A$ and 8-Ph- ${ }^{1}{ }^{H}$ NMR spectrum (400 $\left.\mathrm{MHz}, \mathrm{CDCl}_{3}\right)$. 


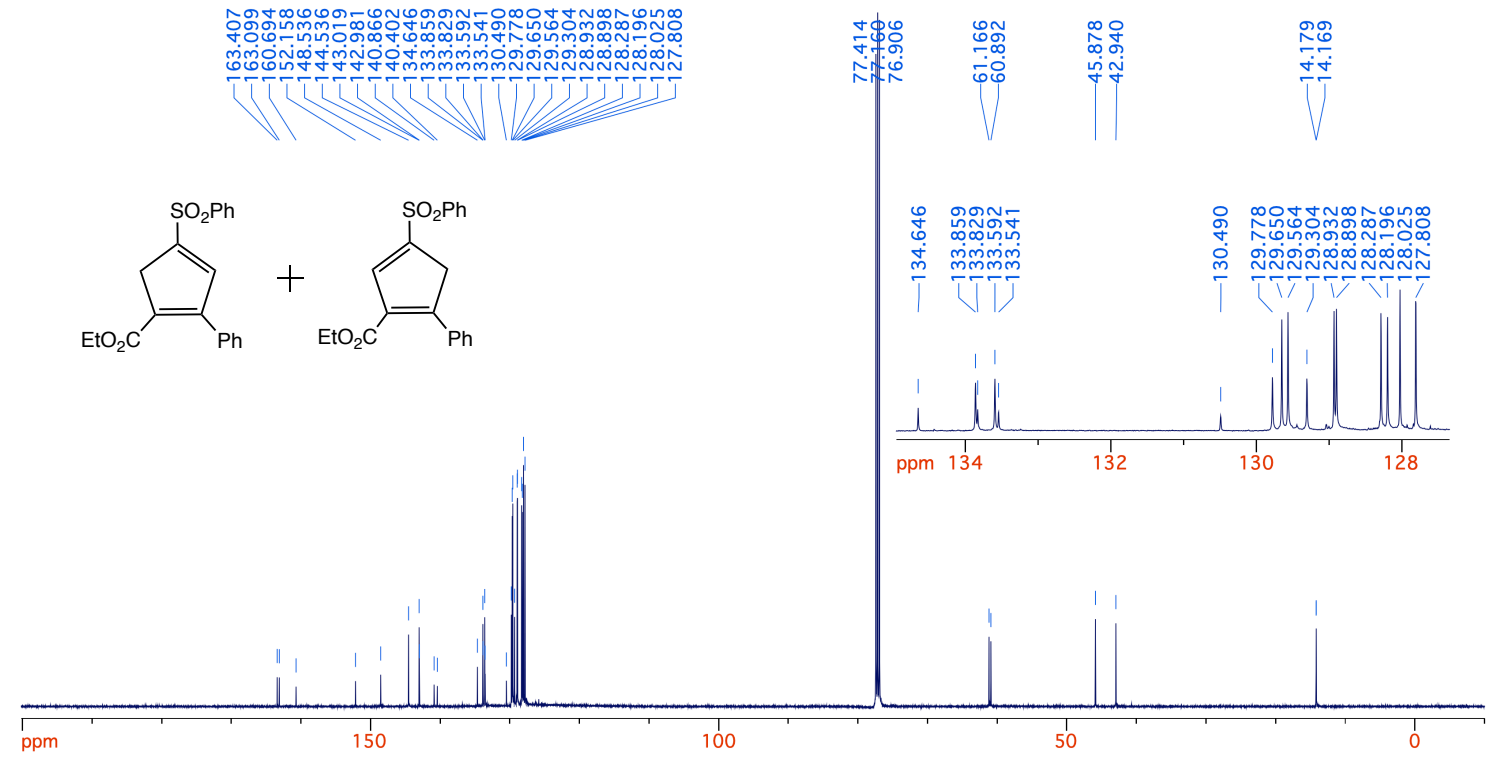

Figure S14. 8-Ph- $A$ and 8-Ph-B ${ }^{13} \mathrm{C}\left\{{ }^{1} \mathrm{H}\right\}$ NMR spectrum (125 $\left.\mathrm{MHz}, \mathrm{CDCl}_{3}\right)$. 


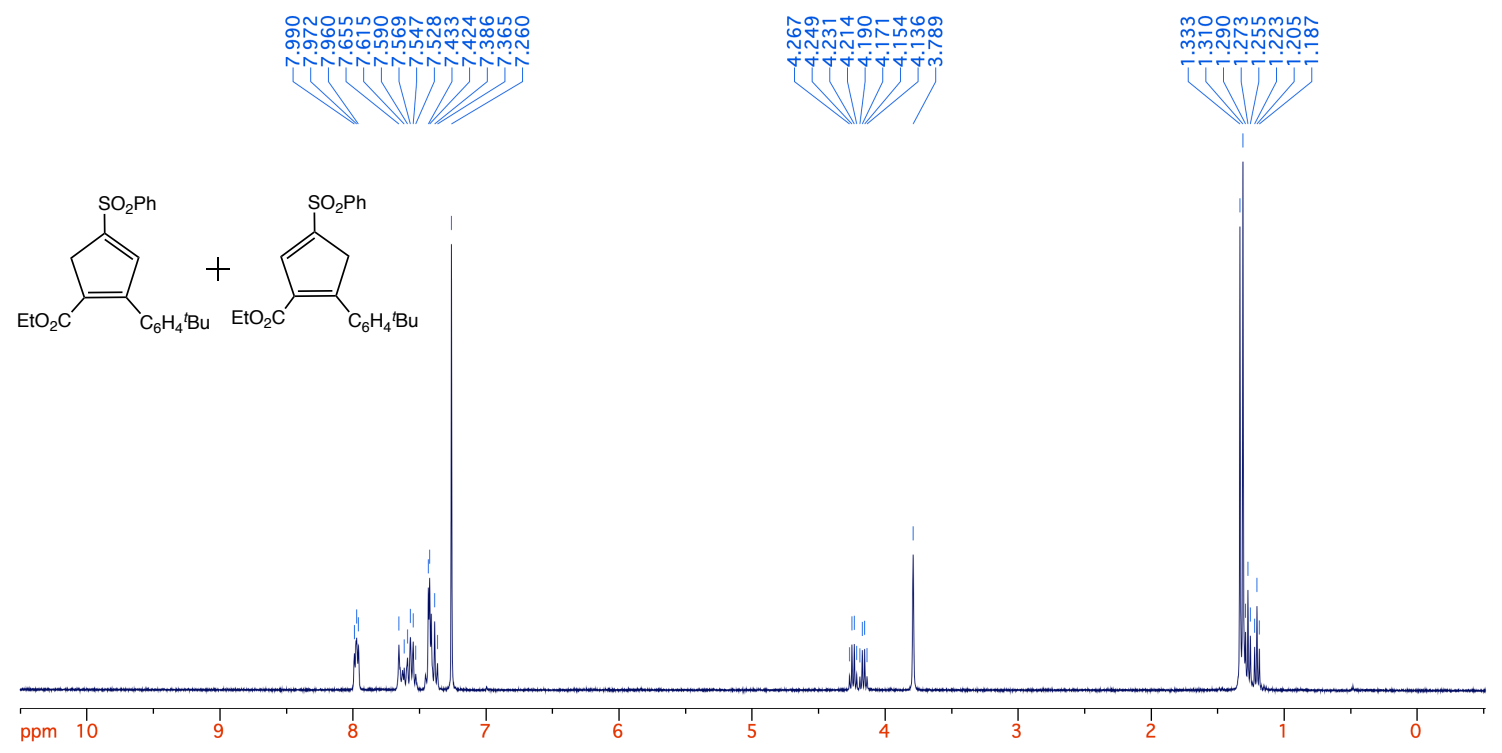

Figure S15. 8- $A r^{t} B u-A$ and 8- $A r^{t} B u-B{ }^{1} \mathrm{H}$ NMR spectrum (400 $\mathrm{MHz}, \mathrm{CDCl}_{3}$ ). 


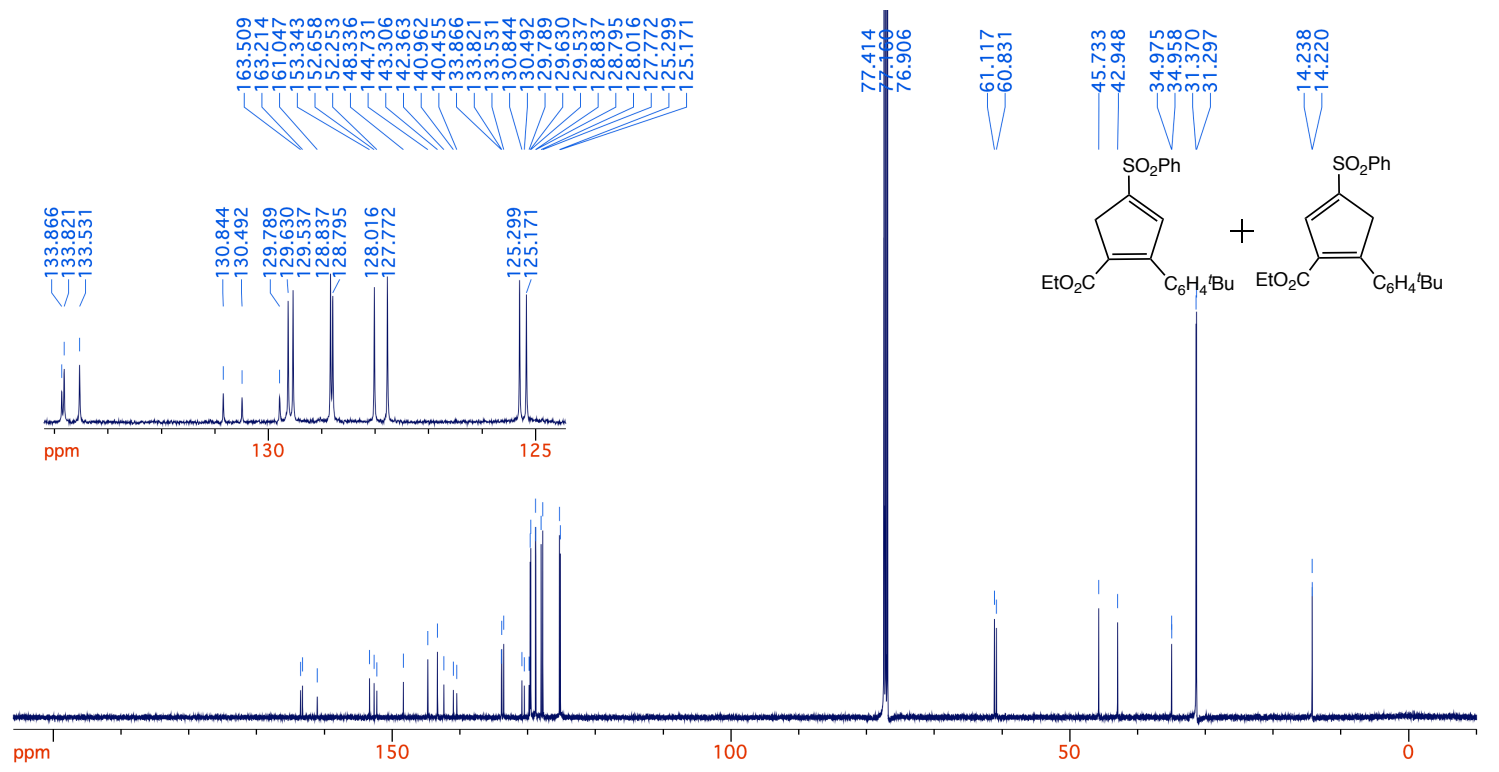

Figure S16. 8- $A r^{t} B u-A$ and $8-A r^{t} B u-B{ }^{13} C\left\{{ }^{1} H\right\}$ NMR spectrum (125 MHz, $\left.\left.C D C l_{3}\right)\right)$. 


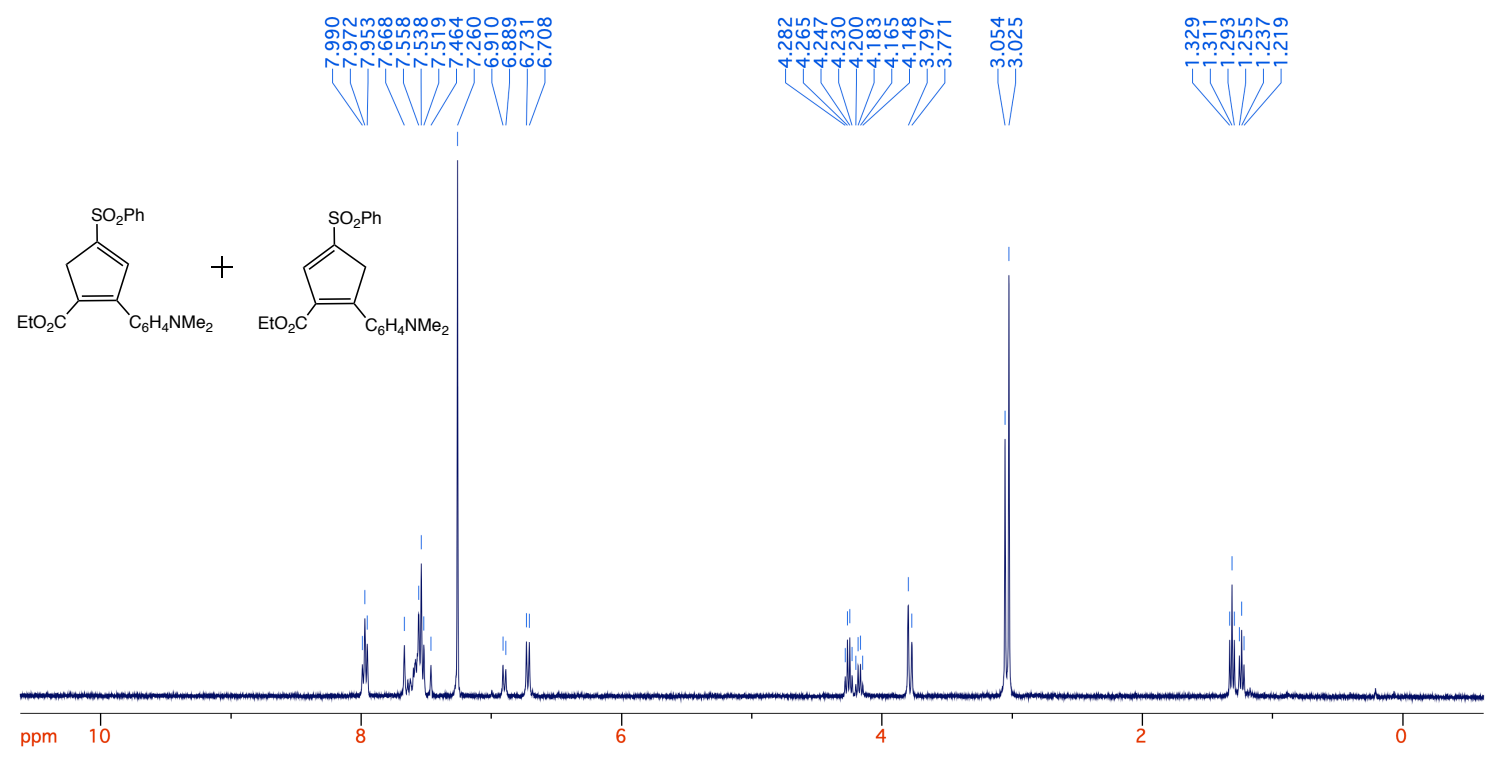

Figure S17. 8- $A r N M e_{2}-A$ and 8- $A r N M e_{2}-B{ }^{1} \mathrm{H}$ NMR spectrum (400 MHz, $\left.\mathrm{CDCl}_{3}\right)$. 


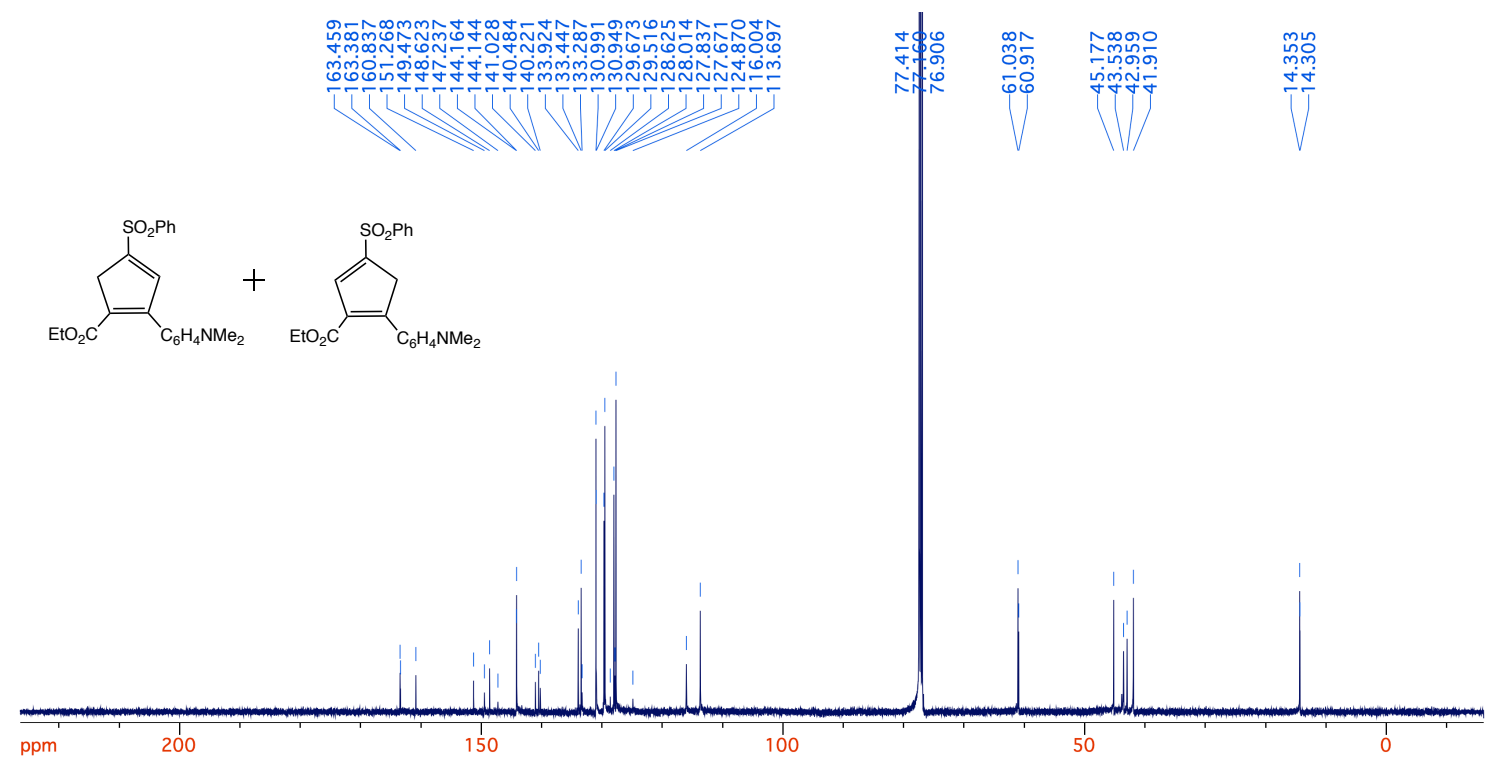

Figure S18. 8- $A r N M e_{2}-A$ and 8- $A r N M e_{2}-B{ }^{13} \mathrm{C}\left\{{ }^{1} \mathrm{H}\right\}$ NMR spectrum (125 $\left.\mathrm{MHz}, \mathrm{CDCl}_{3}\right)$. 


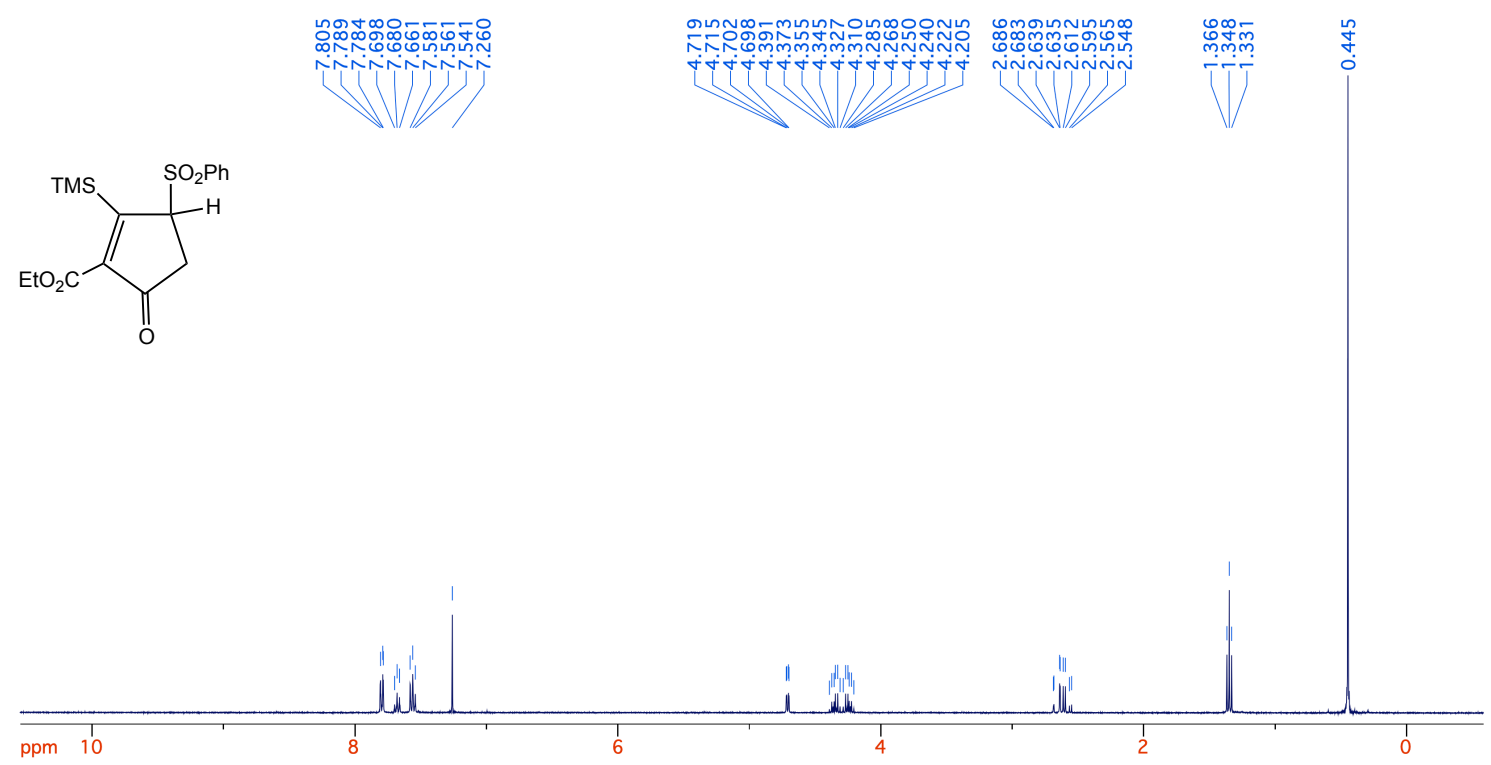

Figure S19. $11^{1} \mathrm{H}$ NMR spectrum (400 $\left.\mathrm{MHz}, \mathrm{CDCl}_{3}\right)$. 


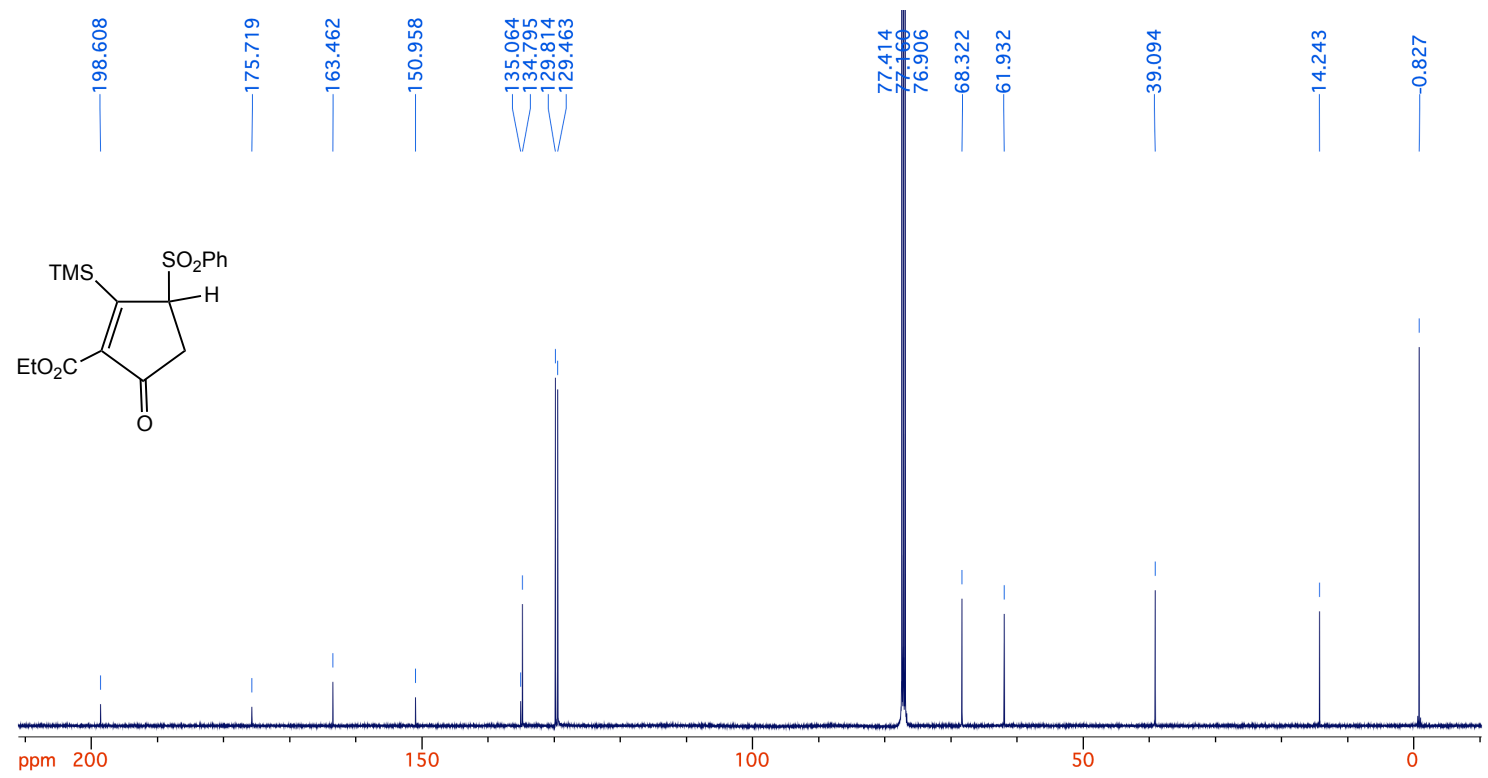

Figure S20. $11{ }^{13} \mathrm{C}\left\{{ }^{1} \mathrm{H}\right\}$ NMR spectrum $\left(125 \mathrm{MHz}, \mathrm{CDCl}_{3}\right)$. 

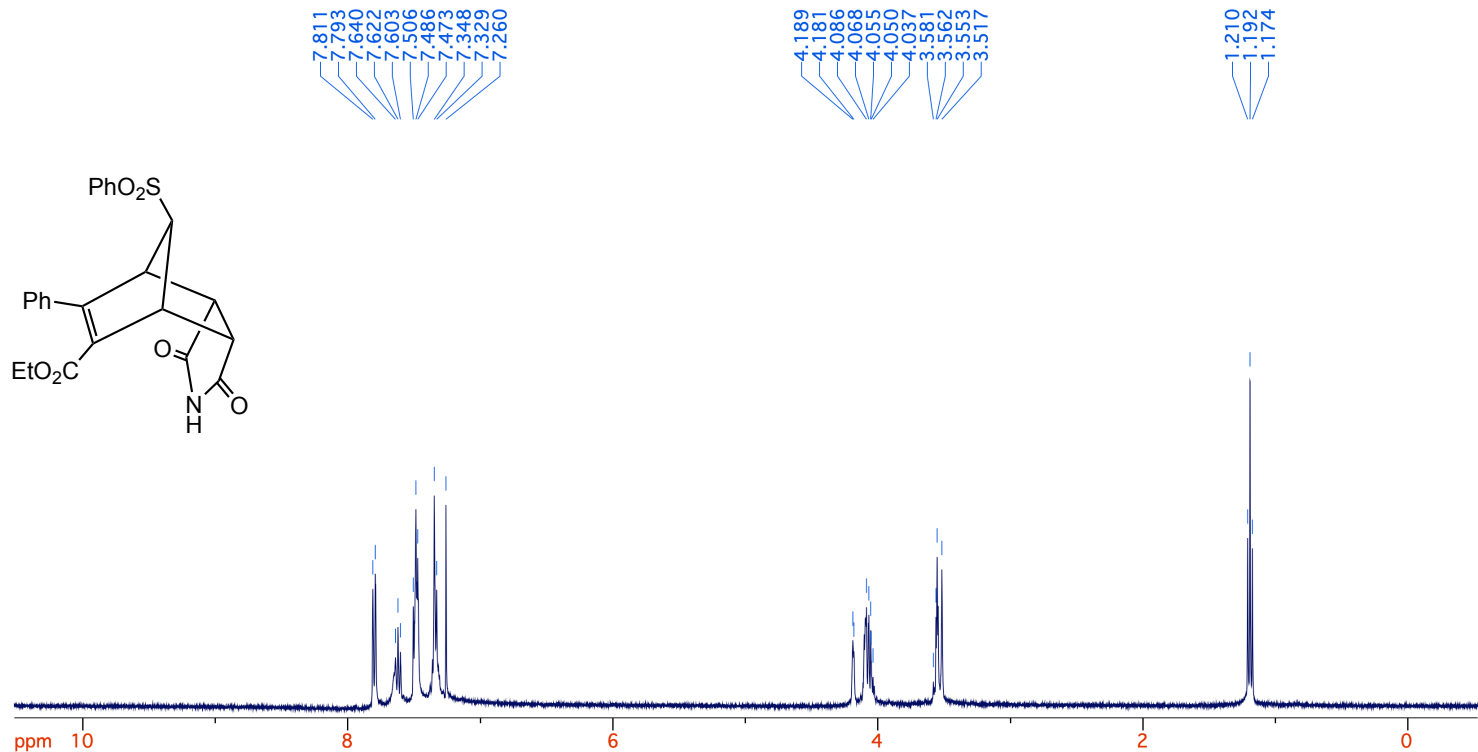

Figure S21. $15^{1} \mathrm{H}$ NMR spectrum (400 $\left.\mathrm{MHz}, \mathrm{CDCl}_{3}\right)$. 


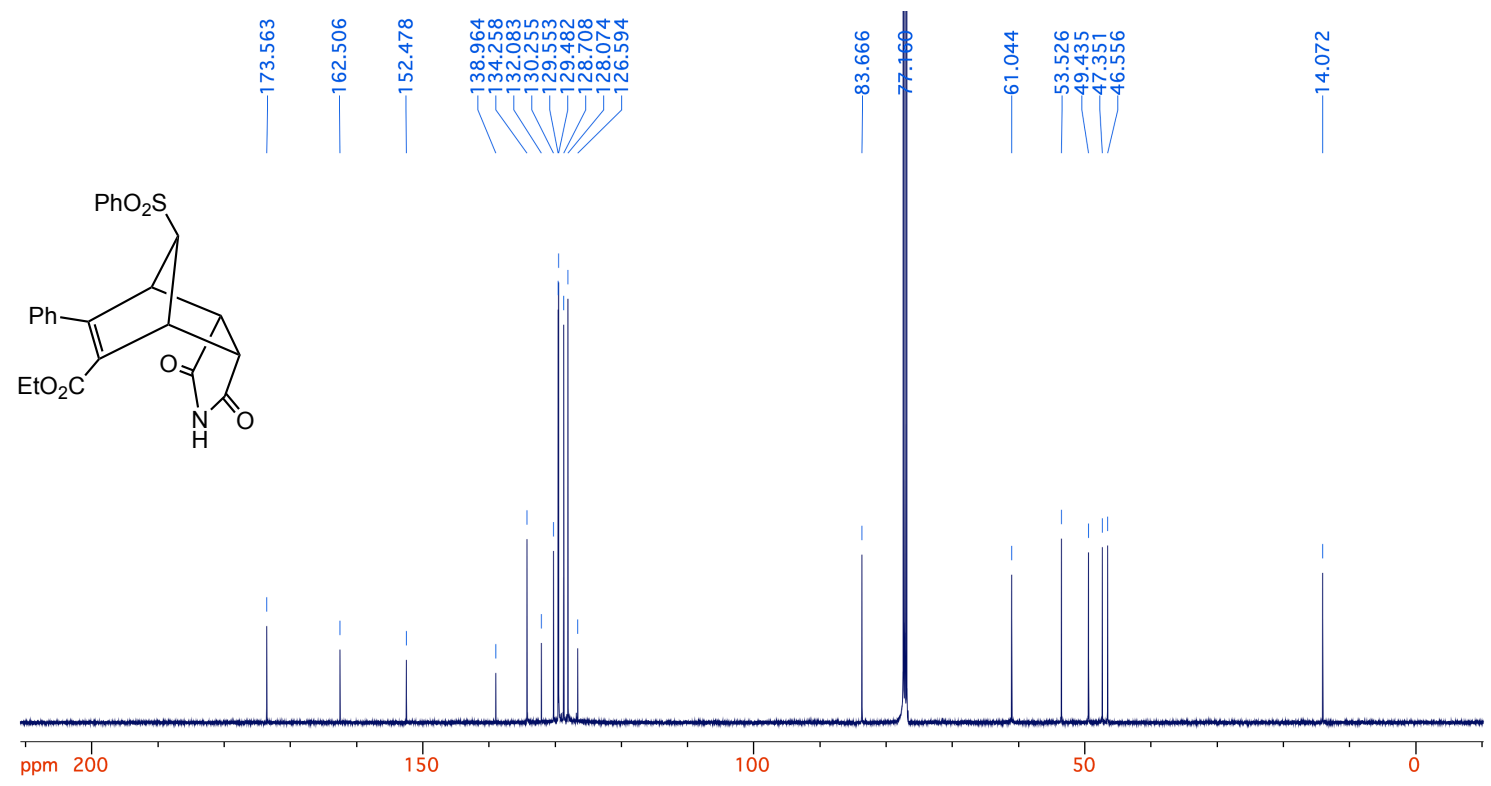

Figure S22. $15{ }^{13} \mathrm{C}\left\{{ }^{1} \mathrm{H}\right\}$ NMR spectrum (125 $\left.\mathrm{MHz}, \mathrm{CDCl}_{3}\right)$. 


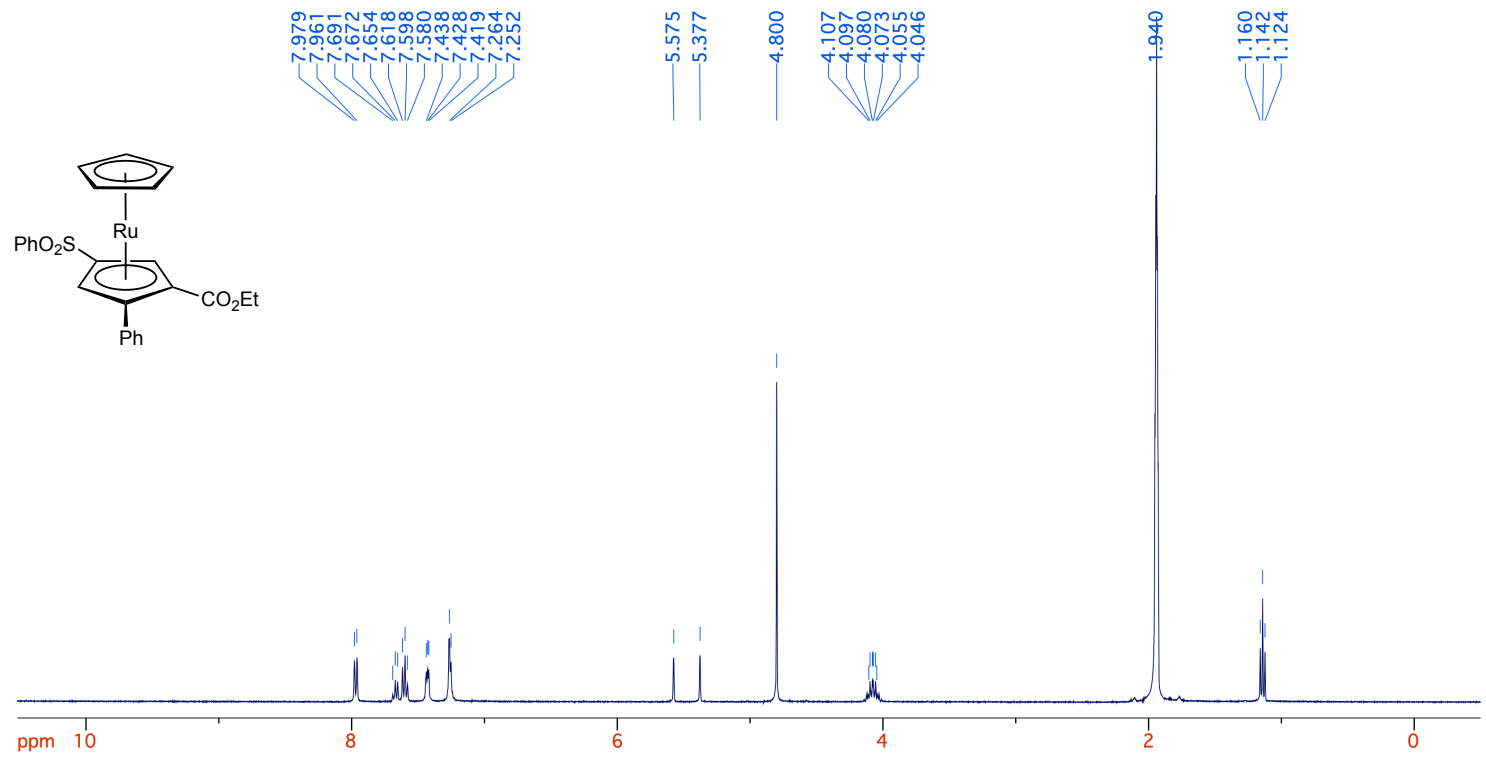

Figure S23. 17-Cp ${ }^{1} \mathrm{H}$ NMR spectrum (400 MHz, NCCD 3 ). 


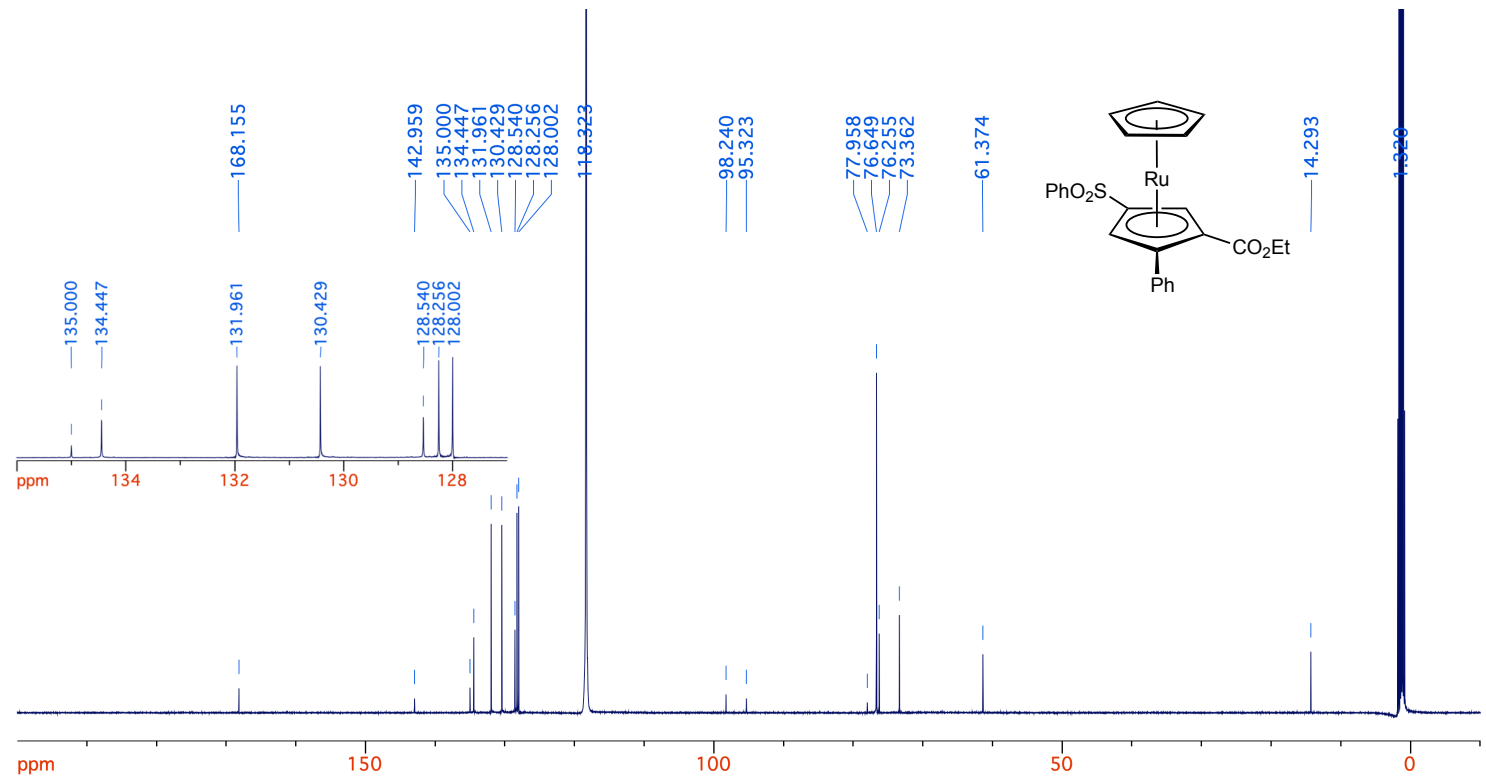

Figure S24. 17-Cp ${ }^{13} \mathrm{C}\left\{{ }^{1} \mathrm{H}\right\}$ NMR spectrum (125 MHz, NCCD 3 ). 


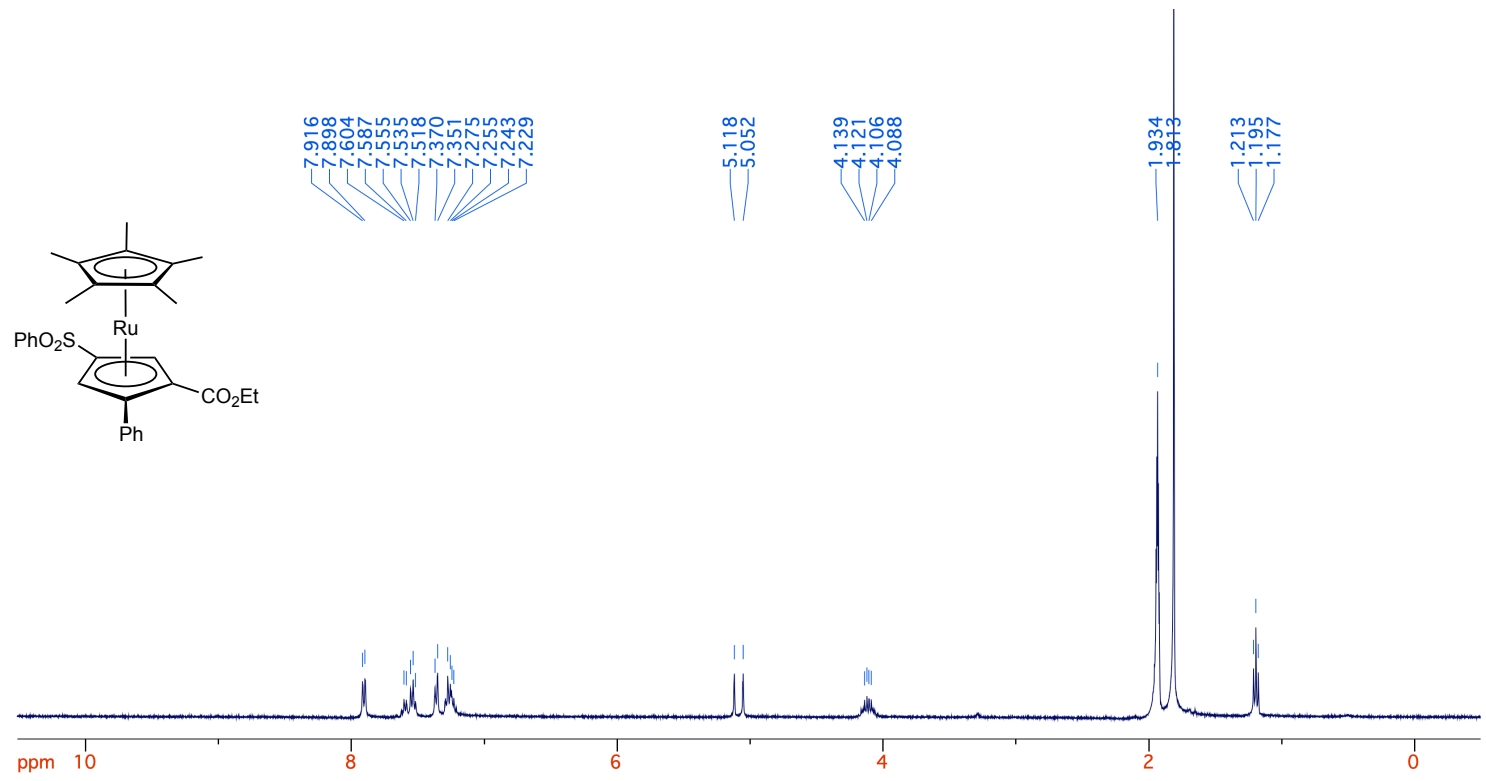

Figure S25. 17- $C p^{* 1} \mathrm{H}$ NMR spectrum (400 MHz, NCCD $)$. 


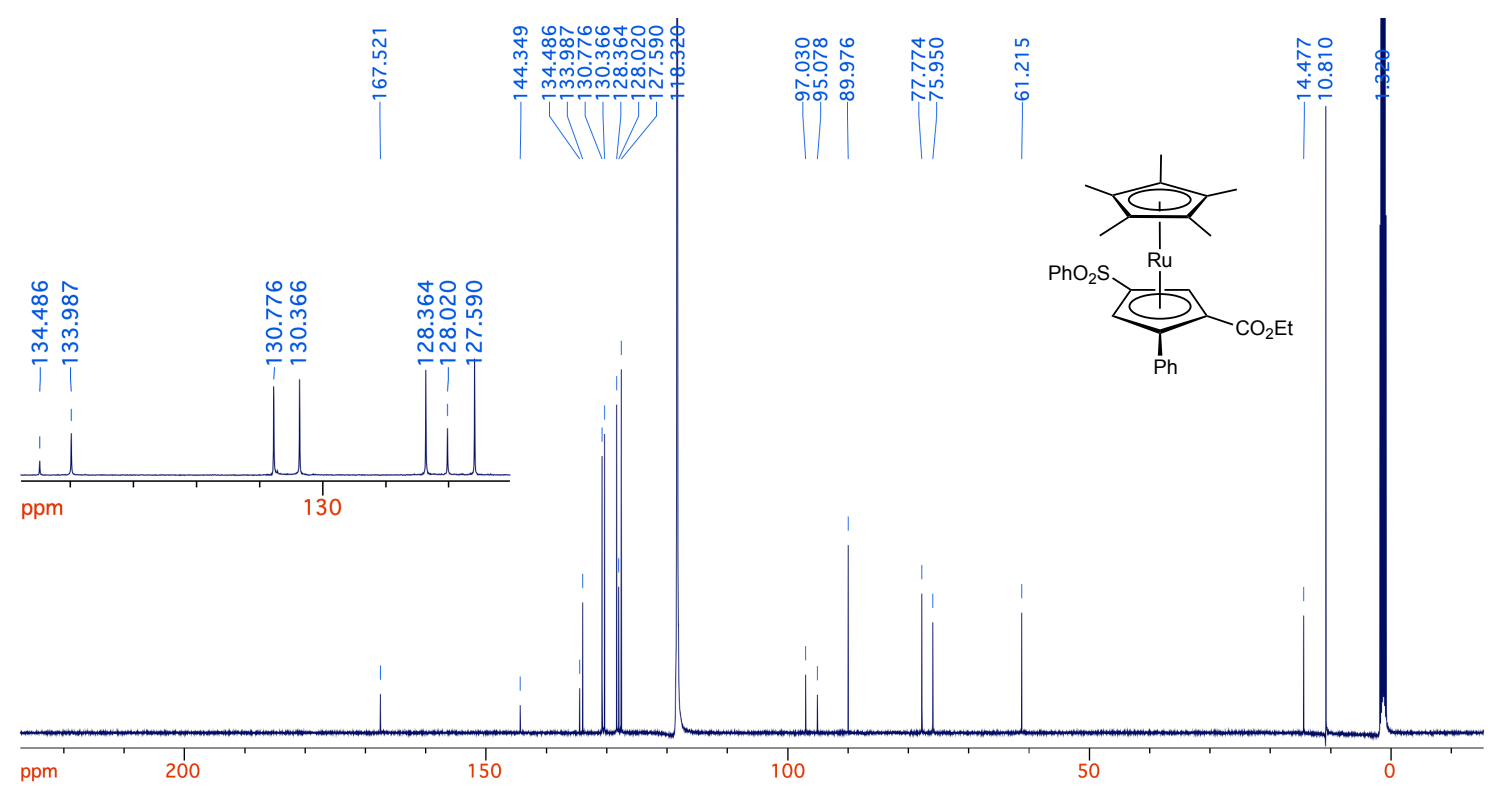

Figure S26. 17-Cp* ${ }^{13} \mathrm{C}\left\{{ }^{1} \mathrm{H}\right\}$ NMR spectrum (125 MHz, NCCD $)$. 


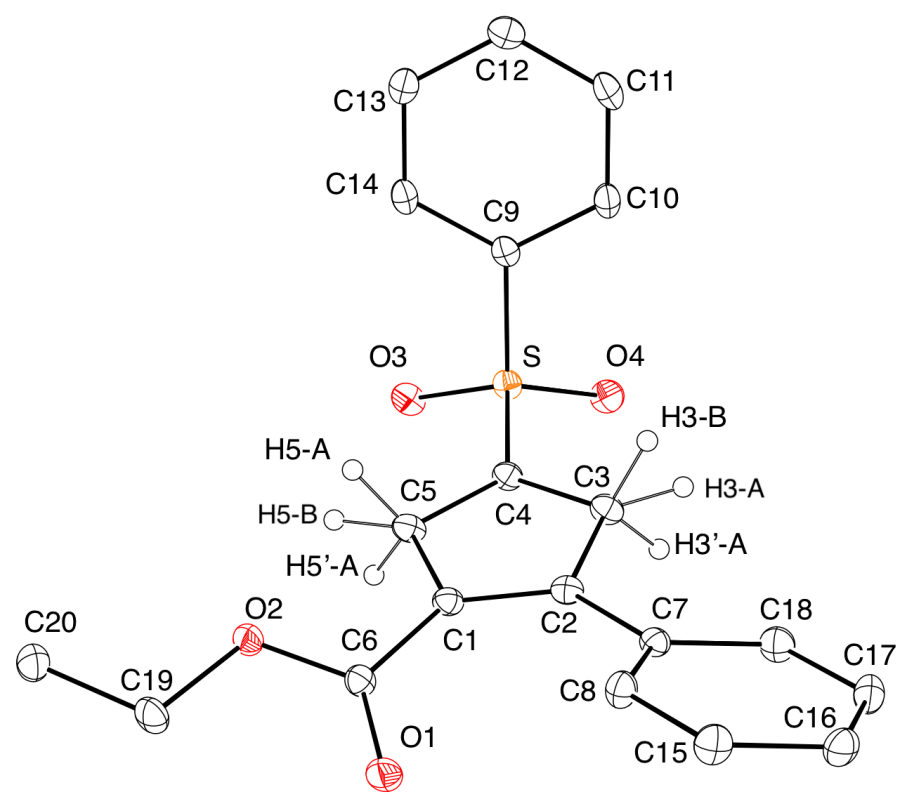

Figure S27. ORTEP of 8-Ph-A/8-Ph-B. Thermal ellipsoids shown at $30 \%$ probability. Most hydrogen atoms are omitted for clarity. The sample was prepared from recrystalliazation in chloroform/hexanes at $-20{ }^{\circ} \mathrm{C}$.

\section{Table S1. Crystal data and structure refinement for 8-Ph-A/8-Ph-B.}

Identification code

Empirical formula

Molecular formula

Formula weight

Temperature

Wavelength

Crystal system

Space group

Unit cell dimensions

Volume

Z

Density (calculated)

Absorption coefficient

$\mathrm{F}(000)$

Crystal size

Crystal color, habit

Theta range for data collection

Index ranges

Reflections collected

Independent reflections

Completeness to theta $=25.000^{\circ}$

Absorption correction

Max. and min. transmission

Refinement method

Data / restraints / parameters

Goodness-of-fit on $\mathrm{F}^{2}$

Final R indices [I $>2 \operatorname{sigma}(\mathrm{I})]$

$\mathrm{R}$ indices (all data)

Extinction coefficient

Largest diff. peak and hole
PQ_0313

C20 H18 O4 S

C20 H18 O4 S

354.40

$100.0 \mathrm{~K}$

$0.71073 \AA$

Monoclinic

P 1 21/n 1

$\mathrm{a}=11.0617(8) \AA$

$\alpha=90^{\circ}$.

$\mathrm{b}=10.3249(8) \AA$

$\mathrm{c}=15.3097(11) \AA$

$1696.6(2) \AA^{3}$

4

$1.388 \mathrm{Mg} / \mathrm{m}^{3}$

$0.213 \mathrm{~mm}^{-1}$

744

$0.297 \times 0.086 \times 0.074 \mathrm{~mm}^{3}$

Light Yellow Needle

2.737 to $25.381^{\circ}$.

$-13<=\mathrm{h}<=13,-8<=\mathrm{k}<=12,-18<=\mathrm{l}<=18$

11890

$3094[\mathrm{R}($ int $)=0.0352, \mathrm{R}($ sigma $)=0.0363]$

$99.6 \%$

Semi-empirical from equivalents

0.0916 and 0.0635

Full-matrix least-squares on $\mathrm{F}^{2}$

3094 / 0 / 227

1.059

$\mathrm{R} 1=0.0406, \mathrm{wR} 2=0.0894$

$\mathrm{R} 1=0.0541, \mathrm{wR} 2=0.0952$

$\mathrm{n} / \mathrm{a}$

0.376 and -0.344 e. $\AA^{-3}$ 


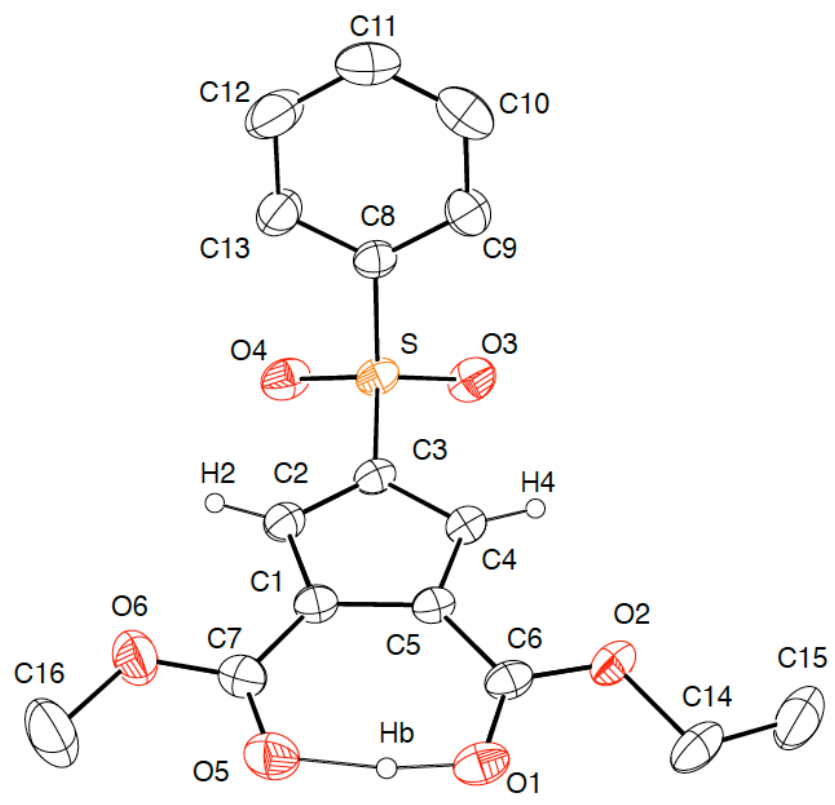

Figure S28. ORTEP of 8- $\mathrm{CO}_{2} \mathrm{Me}$. Thermal ellipsoids shown at 30\% probability. Most hydrogen atoms are omitted for clarity. The sample was prepared from recrystalliazation in $\mathrm{CH}_{2} \mathrm{Cl}_{2} / \mathbf{h e x a n e s}$.

Table S2. Crystal data and structure refinement for $8-\mathrm{CO}_{2} \mathrm{Me}$.

Identification code

Empirical formula

Formula weight

Temperature

Wavelength

Crystal system

Space group

Unit cell dimensions

\section{Volume}

Z

Density (calculated)

Absorption coefficient

$\mathrm{F}(000)$

Crystal size

Theta range for data collection

Index ranges

Reflections collected

Independent reflections

Completeness to theta $=25.02^{\circ}$

Absorption correction

Max. and min. transmission

Refinement method

Data / restraints / parameters

Goodness-of-fit on $\mathrm{F}^{2}$

Final $\mathrm{R}$ indices [I $>2 \operatorname{sigma}(\mathrm{I})]$

$\mathrm{R}$ indices (all data)

Largest diff. peak and hole

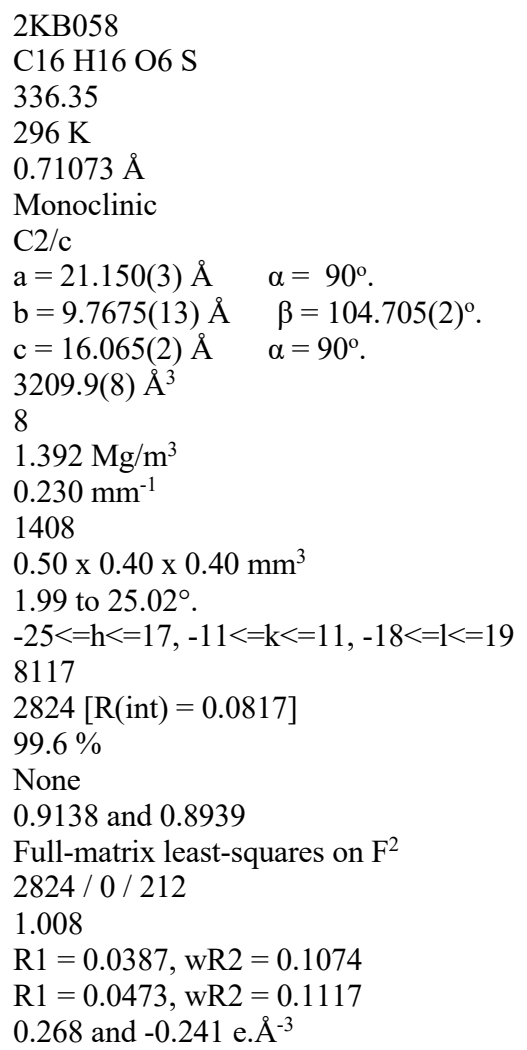




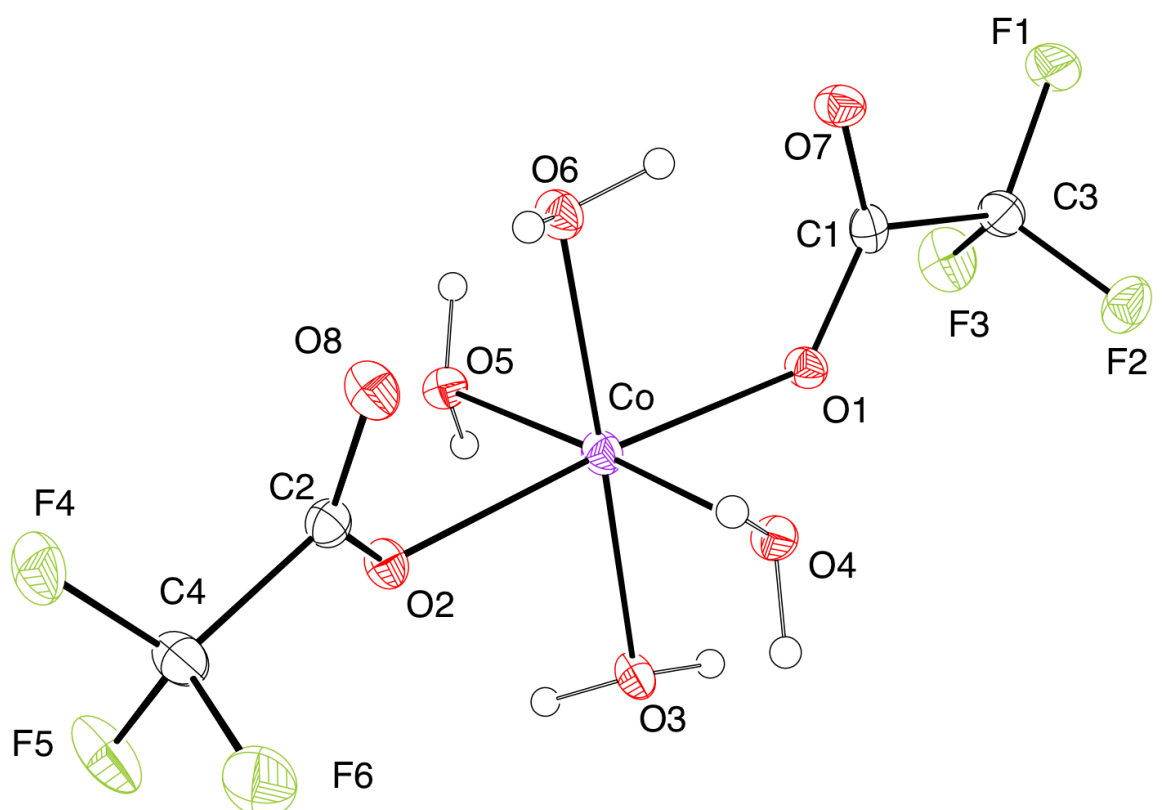

Figure S29. ORTEP of 9. Thermal ellipsoids shown at $30 \%$ probability. The sample was prepared from crystalliazation of the crude oil in the presence of small amount of chloroform overnight.

\section{Table S3. Crystal data and structure refinement for 9.}

Identification code

Empirical formula

Molecular formula

Formula weight

Temperature

Wavelength

Crystal system

Space group

Unit cell dimensions

Volume

Z

Density (calculated)

Absorption coefficient

$\mathrm{F}(000)$

Crystal size

Crystal color, habit

Theta range for data collection

Index ranges

Reflections collected

Independent reflections

Completeness to theta $=25.000^{\circ}$

Absorption correction

Max. and min. transmission

Refinement method

Data / restraints / parameters

Goodness-of-fit on $\mathrm{F}^{2}$

Final R indices [I $>2 \operatorname{sigma}(\mathrm{I})]$

$\mathrm{R}$ indices (all data)

Extinction coefficient

Largest diff. peak and hole
PQ_0331

C4 H8 Co F6 O8

C4 H8 Co F6 O8

357.03

$100.0 \mathrm{~K}$

$0.71073 \AA$

Triclinic

P-1

$\mathrm{a}=8.1249(14) \AA$

$\alpha=75.059(12)^{\circ}$.

$\mathrm{b}=9.0422(14) \AA$

$\beta=64.690(11)^{\circ}$.

$c=9.2650(15) \AA$

$577.49(18) \AA^{3}$

$2.053 \mathrm{Mg} / \mathrm{m}^{3}$

$1.603 \mathrm{~mm}^{-1}$

354

$0.131 \times 0.054 \times 0.042 \mathrm{~mm}^{3}$

Red Needle

2.400 to $25.389^{\circ}$

$-9<=\mathrm{h}<=9,-10<=\mathrm{k}<=10,-11<=1<=11$

4179

$4179[\mathrm{R}(\mathrm{int})=$ ?, $\mathrm{R}($ sigma $)=0.0667]$

$100.0 \%$

Semi-empirical from equivalents

0.091642 and 0.061194

Full-matrix least-squares on $\mathrm{F}^{2}$

4179 / 0 / 177

1.057

$\mathrm{R} 1=0.0551, \mathrm{wR} 2=0.1087$

$\mathrm{R} 1=0.0784, \mathrm{wR} 2=0.1202$

$\mathrm{n} / \mathrm{a}$

0.532 and -0.572 e. $\AA^{-3}$ 


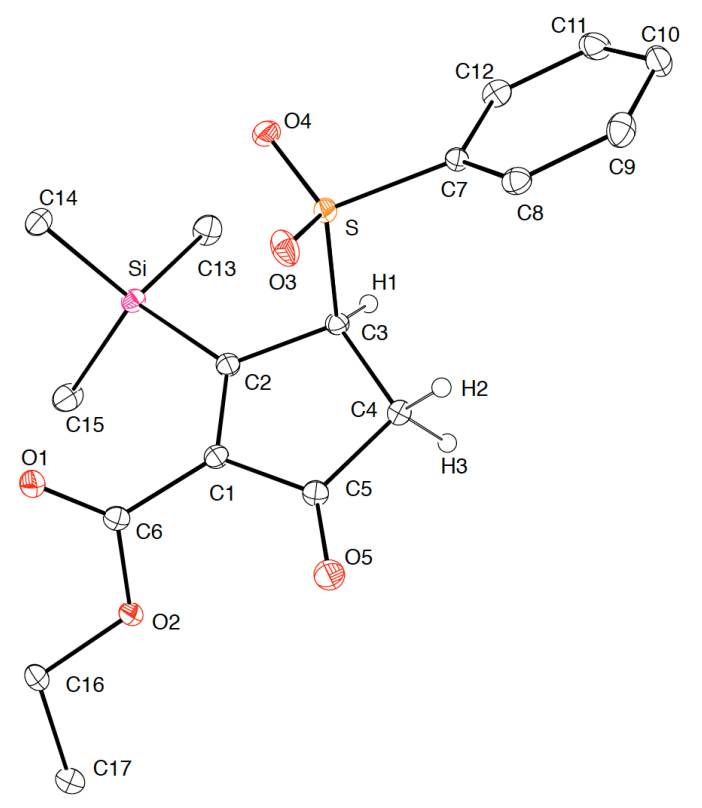

Figure S30. ORTEP of 11 . Thermal ellipsoids shown at 30\% probability. Most hydrogen atoms are omitted for clarity. The sample was prepared from recrystalliazation in chloroform/hexanes at -20 ${ }^{\circ} \mathbf{C}$.

Table S4. Crystal data and structure refinement for 11.

Identification code

Empirical formula

Molecular formula

Formula weight

Temperature

Wavelength

Crystal system

Space group

Unit cell dimensions

Volume

Z

Density (calculated)

Absorption coefficient

$\mathrm{F}(000)$

Crystal size

Crystal color, habit

Theta range for data collection

Index ranges

Reflections collected

Independent reflections

Completeness to theta $=25.000^{\circ}$

Absorption correction

Max. and min. transmission

Refinement method

Data / restraints / parameters

Goodness-of-fit on $\mathrm{F}^{2}$

Final R indices [I $>2 \operatorname{sigma}(\mathrm{I})]$

$\mathrm{R}$ indices (all data)

Extinction coefficient

Largest diff. peak and hole
PQ 0323

C17 $\mathrm{H} 22$ O5 S Si

C17 H22 O5 S Si

366.49

$100.0 \mathrm{~K}$

$0.71073 \AA$

Monoclinic

P $121 / \mathrm{c} 1$

$\mathrm{a}=15.5019(8) \AA$

$\mathrm{b}=8.5732(5) \AA$

$\mathrm{c}=14.4028(8) \AA$

$\alpha=90^{\circ}$.

$\beta=107.173(2)^{\circ}$.

1828.81(18) $\AA^{3}$

$\gamma=90^{\circ}$.

4

$1.331 \mathrm{Mg} / \mathrm{m}^{3}$

$0.265 \mathrm{~mm}^{-1}$

776

$0.346 \times 0.317 \times 0.294 \mathrm{~mm}^{3}$

Colorless Block

2.745 to $25.786^{\circ}$.

$-18<=\mathrm{h}<=14,-10<=\mathrm{k}<=10,-16<=\mathrm{l}<=17$

31136

$3508[\mathrm{R}($ int $)=0.0467, \mathrm{R}($ sigma $)=0.0274]$

$100.0 \%$

Semi-empirical from equivalents

0.0921 and 0.0667

Full-matrix least-squares on $\mathrm{F}^{2}$

$3508 / 0 / 221$

1.051

$\mathrm{R} 1=0.0349, \mathrm{wR} 2=0.0845$

$\mathrm{R} 1=0.0456, \mathrm{wR} 2=0.0905$

$\mathrm{n} / \mathrm{a}$

0.398 and -0.377 e. $\AA^{-3}$ 


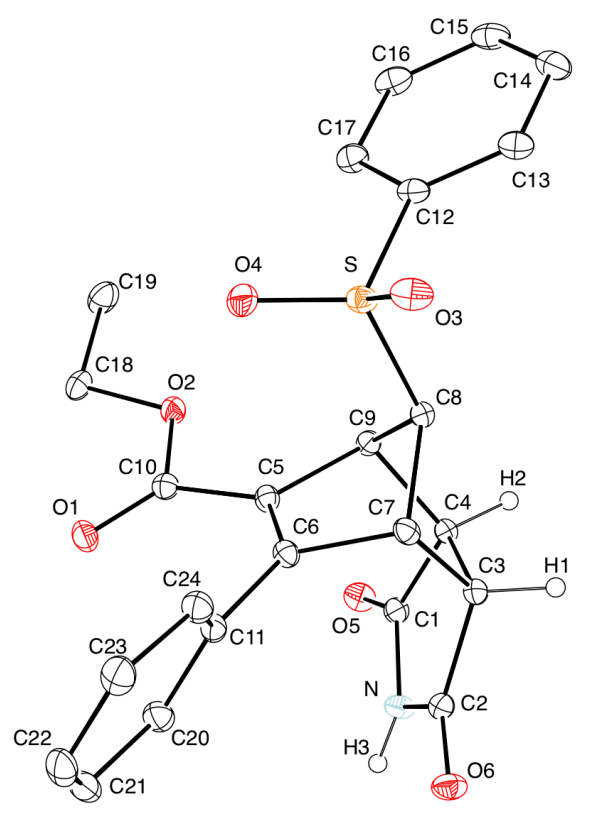

Figure S31. ORTEP of 15 . Thermal ellipsoids shown at 30\% probability. Most hydrogen atoms are omitted for clarity. The sample was prepared from recrystalliazation in chloroform/hexanes.

Table S5. Crystal data and structure refinement for 15.

Identification code

Empirical formula

PQ 0388

Molecular formula

Formula weight

Temperature

Wavelength

Crystal system

Space group

Unit cell dimensions

Volume

Z

Density (calculated)

Absorption coefficient

$\mathrm{F}(000)$

Crystal size

Crystal color, habit

Theta range for data collection

Index ranges

Reflections collected

Independent reflections

Completeness to theta $=25.000^{\circ}$

Absorption correction

Max. and min. transmission

Refinement method

Data / restraints / parameters

Goodness-of-fit on $\mathrm{F}^{2}$

Final R indices [I $>2 \operatorname{sigma}(\mathrm{I})]$

$\mathrm{R}$ indices (all data)

Extinction coefficient

Largest diff. peak and hole

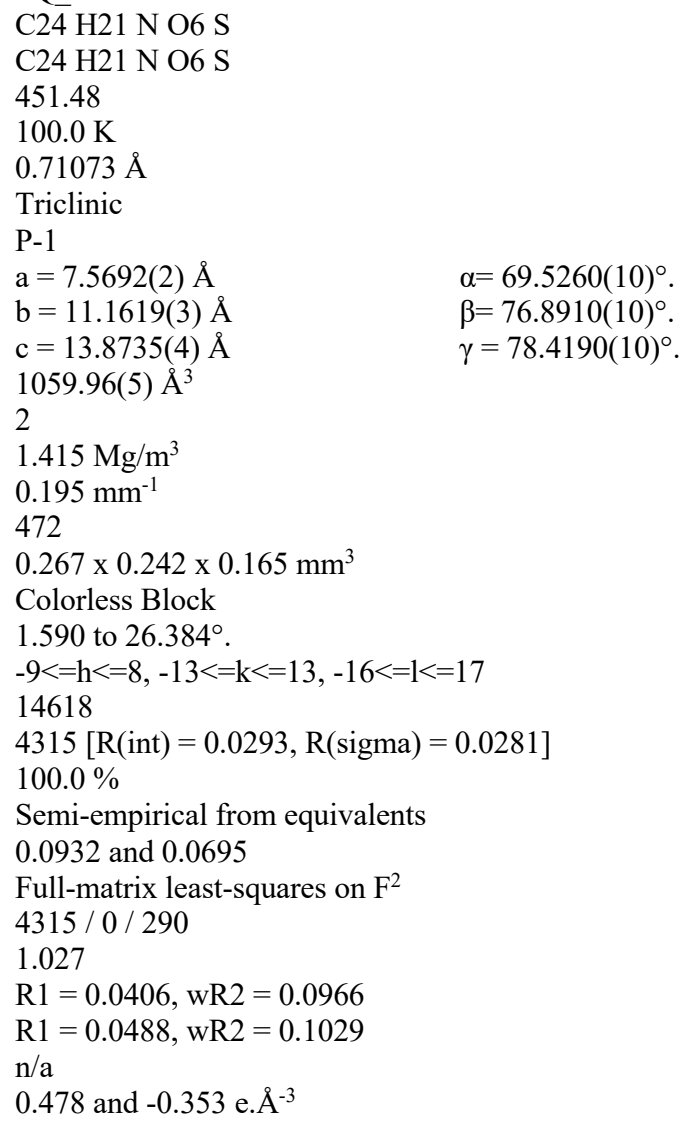




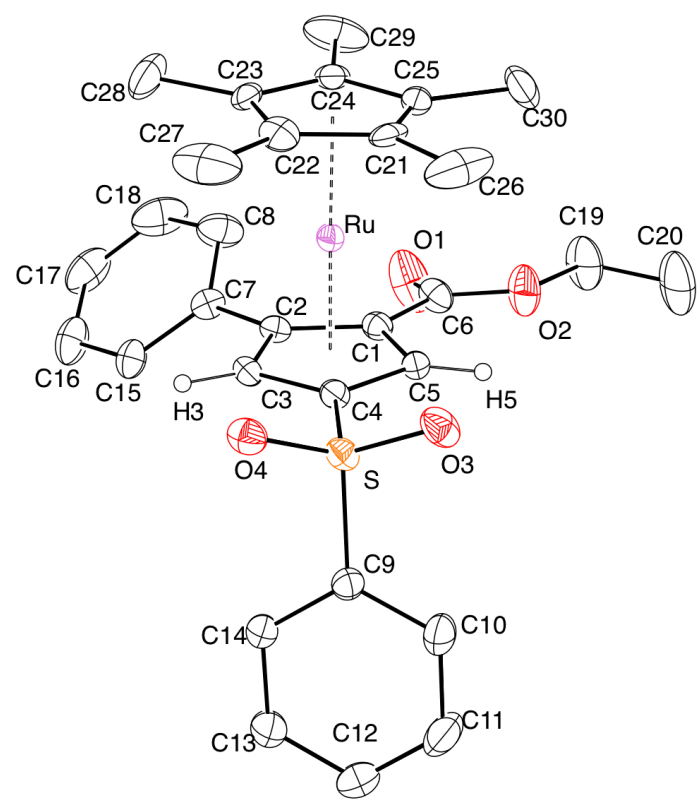

Figure S32. ORTEP of $17-C p^{*}$. Thermal ellipsoids shown at 30\% probability. Most hydrogen atoms are omitted for clarity. The sample was prepared from recrystalliazation in toluenes/hexanes at $\mathbf{- 2 0}$ ${ }^{\circ} \mathrm{C}$.

Table S6. Crystal data and structure refinement for $17-C_{p}$ *.

Identification code

Empirical formula

Molecular formula

Formula weight

Temperature

Wavelength

Crystal system

Space group

Unit cell dimensions

Volume

Z

Density (calculated)

Absorption coefficient

$\mathrm{F}(000)$

Crystal size

Crystal color, habit

Theta range for data collection

Index ranges

Reflections collected

Independent reflections

Completeness to theta $=25.000^{\circ}$

Absorption correction

Max. and min. transmission

Refinement method

Data / restraints / parameters

Goodness-of-fit on $\mathrm{F}^{2}$

Final R indices [I $>2 \operatorname{sigma}(\mathrm{I})]$

$\mathrm{R}$ indices (all data)

Extinction coefficient

Largest diff. peak and hole
OCon_PQ389

$\mathrm{C} 30 \mathrm{H} 32 \mathrm{O} 4 \mathrm{Ru} \mathrm{S}$

$\mathrm{C} 30 \mathrm{H} 32 \mathrm{O} 4 \mathrm{Ru} \mathrm{S}$

589.68

$100.0 \mathrm{~K}$

$0.71073 \AA$

Monoclinic

P 1 21/c 1

$\mathrm{a}=15.5730(11) \AA$

$\alpha=90^{\circ}$.

$\mathrm{b}=15.4582(11) \AA$

$\mathrm{c}=11.9655(9) \AA$

$\beta=106.128(2)^{\circ}$.

2767.1(3) $\AA^{3}$

4

$1.415 \mathrm{Mg} / \mathrm{m}^{3}$

$0.675 \mathrm{~mm}^{-1}$

1216

$0.217 \times 0.153 \times 0.131 \mathrm{~mm}^{3}$

Light Yellow Rod

1.361 to $26.431^{\circ}$.

$-19<=\mathrm{h}<=19,-19<=\mathrm{k}<=19,-14<=\mathrm{l}<=13$

58579

$5688[\mathrm{R}($ int $)=0.0661, \mathrm{R}($ sigma $)=0.0376]$

$100.0 \%$

Semi-empirical from equivalents

0.2468 and 0.2041

Full-matrix least-squares on $\mathrm{F}^{2}$

$5688 / 152$ / 432

1.043

$\mathrm{R} 1=0.0300, \mathrm{wR} 2=0.0743$

$\mathrm{R} 1=0.0383, \mathrm{wR} 2=0.0814$

$\mathrm{n} / \mathrm{a}$

0.438 and -0.569 e. $\AA^{-3}$ 


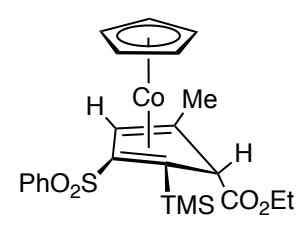

1-Me

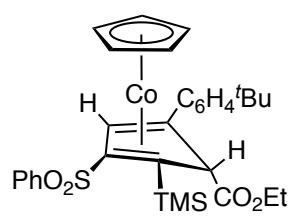

1-Art Bu

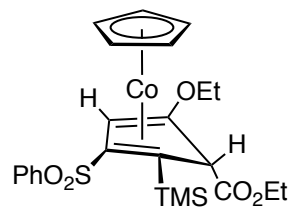

1-OEt<smiles>CCOC(=O)C1=C(c2ccccc2)CC(S(=O)(=O)c2ccccc2)=C1</smiles>

8-Ph-B<smiles>CCCCC1=C(C(=O)OCC)C=C(S(=O)(=O)c2ccccc2)C1</smiles>

8- $\mathrm{ArNMe}_{2}-\mathrm{B}$<smiles>CCOC(=O)C1=C(c2ccccc2)C2C3C(=O)NC(=O)C(C3C1=O)C2c1ccccc1</smiles>

15
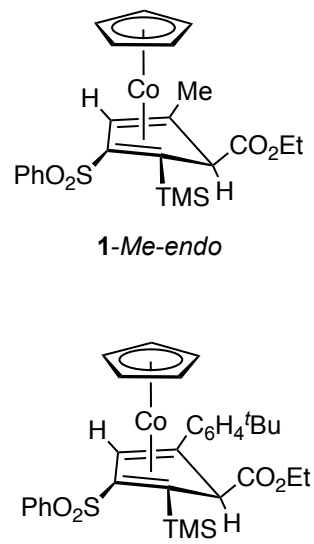

1-Ar'Bu-endo

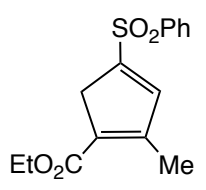

8-Me-A<smiles>CCCCC1=C(C(=O)OCC)CC(S(=O)(=O)c2ccccc2)=C1</smiles>

8-Ar'Bu-A<smiles>CCOC1=C2C=C(S(=O)(=O)c3ccccc3)C=C2C(=O)O[CH]1</smiles>

8- $\mathrm{CO}_{2} \mathrm{Me}$

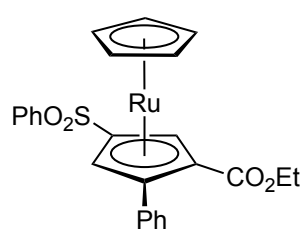

17-Cp

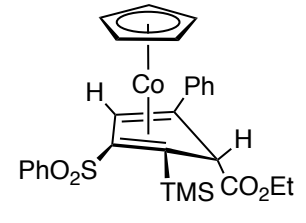

1-Ph

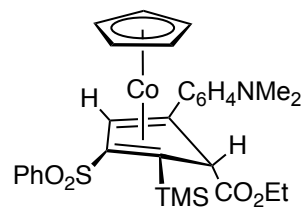

1- $\mathrm{ArNMe}_{2}$

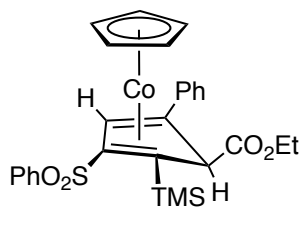

1-Ph-endo

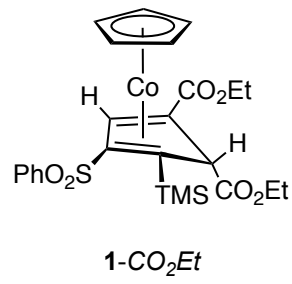<smiles>CCOC(=O)C1=C(C)CC(S(=O)(=O)c2ccccc2)=C1</smiles>

8-Me-B<smiles>CCOC(=O)C1=C(c2ccccc2)C=C(S(=O)(=O)c2ccccc2)C1</smiles>

8-Ph-A<smiles>CCCCC1=C(C(=O)OCC)C=C(S(=O)(=O)c2ccccc2)C1</smiles>

8- $A r^{t} B u-B$<smiles>CCOC(=O)C1=C(CCNC(C)C)C=C(S(=O)(=O)c2ccccc2)C1</smiles>

8- $\mathrm{ArNMe}_{2}-\mathrm{A}$<smiles></smiles>

9

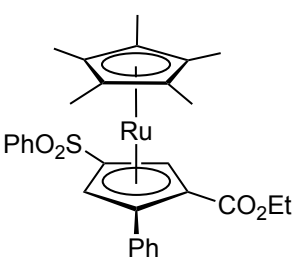

$17-C p^{*}$

Figure S33. Compound Index 
Table S7. Computational results, Z-matrices or Cartesian coordinates, the number of imaginary frequencies, and computed total energies.

\begin{tabular}{|l|l|l|l|}
\hline B97D/Def2-TZVPP trichloromethane & Hessian & Free Energy & $\Delta \mathbf{G}$ \\
\hline cocyclopentadieneIsoA & PD & -1471.459149 & 0 \\
\hline cocyclopentadieneIsoB & PD & -1471.449297 & 6.18 \\
\hline cocyclopentadieneIsoB_3 & PD & -1471.454241 & 3.08 \\
\hline cocyclopentadieneIsoC & PD & -1471.45877 & 0.24 \\
\hline cocyclopentadieneIsoD & PD & -1471.453144 & 3.77 \\
\hline cocyclopentadieneIsoE & PD & -1471.453259 & 3.70 \\
\hline cocyclopentadieneIsoANMe2 & & & \\
\hline cocyclopentadieneIsoCNMe2 & PD & -1605.329577 & 0.31 \\
\hline
\end{tabular}

cocyclopentadieneIsoA

$\begin{array}{lllc}\mathrm{C} & -0.1127425941 & 1.2183477507 & -0.6097285657 \\ \mathrm{H} & -0.2440680765 & 2.2929261524 & -0.5537517789 \\ \mathrm{C} & -1.0655340314 & 0.3130519641 & -0.9314586895 \\ \mathrm{C} & 0.927872002 & -0.828295331 & -0.4885828842 \\ \mathrm{C} & 1.1395272538 & 0.519520678 & -0.3141238699 \\ \mathrm{C} & -0.5087168051 & -1.0742278858 & -0.8687686565 \\ \mathrm{H} & -0.6043555132 & -1.6061977014 & -1.8259109696 \\ \mathrm{H} & -1.0204925886 & -1.6965616223 & -0.120154104 \\ \mathrm{~S} & -2.7314401647 & 0.6986603572 & -1.3525354565 \\ \mathrm{O} & -2.8586468941 & 2.1481986007 & -1.4295199685 \\ \mathrm{O} & -3.1052808021 & -0.1172520526 & -2.5018266703 \\ \mathrm{C} & -3.653544438 & 0.1194201075 & 0.0710319873 \\ \mathrm{C} & -5.0359943526 & -0.7846152567 & 2.3031882825 \\ \mathrm{C} & -3.7411078788 & 0.9419429861 & 1.2009155956 \\ \mathrm{C} & -4.2422629223 & -1.149169308 & 0.0420007021 \\ \mathrm{C} & -4.9388105679 & -1.5969023463 & 1.1680382063 \\ \mathrm{C} & -4.4395013312 & 0.4825319994 & 2.3189532037 \\ \mathrm{H} & -3.2759076938 & 1.9232102711 & 1.1999888583 \\ \mathrm{H} & -4.1619685456 & -1.7671940415 & -0.8467584389 \\ \mathrm{H} & -5.4054235272 & -2.5784588114 & 1.1561882723 \\ \mathrm{H} & -4.5191920964 & 1.1133747023 & 3.2004708869 \\ \mathrm{H} & -5.5780928618 & -1.1380532325 & 3.1767542295 \\ \mathrm{C} & 2.3341858923 & 1.239907283 & 0.1511454116 \\ \mathrm{C} & 4.5873921726 & 2.666627437 & 1.0489862583 \\ \mathrm{C} & 3.1203015392 & 0.7442658605 & 1.2069208675 \\ & & & \end{array}$




$\begin{array}{llcl}\mathrm{C} & 2.6799339959 & 2.4733836608 & -0.4318524006 \\ \mathrm{C} & 3.8047723962 & 3.1754862945 & 0.0068029203 \\ \mathrm{C} & 4.2368721496 & 1.4517044711 & 1.6513447657 \\ \mathrm{H} & 2.8445305871 & -0.191412643 & 1.6827038757 \\ \mathrm{H} & 2.0743728713 & 2.8715376176 & -1.2424371691 \\ \mathrm{H} & 4.0677943095 & 4.1201175081 & -0.4631087765 \\ \mathrm{H} & 4.8318540073 & 1.0581438701 & 2.4721188399 \\ \mathrm{H} & 5.4591146071 & 3.2164147293 & 1.3957654993 \\ \mathrm{C} & 1.8504003162 & -1.9726696699 & -0.3753688974 \\ \mathrm{O} & 1.4709616325 & -3.1080386178 & -0.1199482986 \\ \mathrm{O} & 3.1331701692 & -1.6387674256 & -0.635382888 \\ \mathrm{C} & 4.1526962337 & -2.6732428998 & -0.4629787344 \\ \mathrm{H} & 3.7660438363 & -3.6220788376 & -0.8472433492 \\ \mathrm{H} & 4.9784424101 & -2.3314897567 & -1.092503913 \\ \mathrm{C} & 4.571780462 & -2.7867071054 & 0.9962407819 \\ \mathrm{H} & 3.72791591 & -3.1031581151 & 1.6184673549 \\ \mathrm{H} & 4.9507023474 & -1.8274019159 & 1.3651586744 \\ \mathrm{H} & 5.369006584 & -3.535589725 & 1.0821880054\end{array}$

\section{cocyclopentadieneIsoB_3}

$\begin{array}{llll}\mathrm{C} & -0.848927972 & 1.0749710372 & 0.8347385835 \\ \mathrm{H} & -1.3263526757 & 1.553827399 & 1.6991999465 \\ \mathrm{C} & -0.7162562393 & -0.4100468891 & 0.9366626547 \\ \mathrm{H} & -1.5423730743 & -1.089157077 & 1.1019326024 \\ \mathrm{C} & 0.5718376858 & -0.7482502674 & 0.6871806677 \\ \mathrm{C} & 1.370675862 & 0.4815743096 & 0.4373119183 \\ \mathrm{C} & 0.5364544315 & 1.5493710482 & 0.5341035074 \\ \mathrm{H} & 0.8108772221 & 2.5925941025 & 0.4436302103 \\ \mathrm{C} & 1.0425979971 & -2.1433576265 & 0.4895747761 \\ \mathrm{O} & 1.8601167663 & -2.4705345902 & -0.3530031462 \\ \mathrm{O} & 0.4231538265 & -3.0026657946 & 1.3258534728 \\ \mathrm{C} & 0.7347176819 & -4.42298302 & 1.1497650107 \\ \mathrm{H} & 0.4806438276 & -4.7037404668 & 0.1216712 \\ \mathrm{H} & 1.8127901717 & -4.5559982837 & 1.2921073819 \\ \mathrm{C} & -0.0764553837 & -5.1963053012 & 2.1717139311 \\ \mathrm{H} & -1.150572013 & -5.0415113505 & 2.0169957754 \\ \mathrm{H} & 0.1849893209 & -4.8904646287 & 3.191319392 \\ \mathrm{H} & 0.1404646374 & -6.2656984205 & 2.062597184 \\ \mathrm{~S} & -1.9760564207 & 1.5441570954 & -0.5744942206 \\ \mathrm{O} & -2.1084302425 & 2.994859469 & -0.5351584112 \\ \mathrm{O} & -1.5014102471 & 0.9029320565 & -1.7915828323 \\ \mathrm{C} & 2.8202764101 & 0.5516099869 & 0.2057983975 \\ \mathrm{C} & 5.6015282702 & 0.7779508025 & -0.1742875812 \\ \mathrm{C} & 3.3479318427 & 1.5128580364 & -0.6769261358 \\ \mathrm{C} & 3.7086497569 & -0.2957877324 & 0.89295149 \\ \mathrm{C} & 5.0871165366 & -0.1800172515 & 0.7073748916 \\ \mathrm{C} & 4.7265396175 & 1.6238788985 & -0.8660370291 \\ \mathrm{H} & 2.6666146601 & 2.1588696536 & -1.224982168 \\ \mathrm{H} & 3.3189403983 & -1.0369117833 & 1.5848614342 \\ \mathrm{H} & 5.7606816764 & -0.8385379046 & 1.2508080912 \\ \mathrm{H} & 5.1179118582 & 2.3652619719 & -1.5587954464\end{array}$




$\begin{array}{llll}\mathrm{H} & 6.6753564541 & 0.8616100476 & -0.3241071691 \\ \mathrm{C} & -3.5356305002 & 0.8056621141 & -0.0970765472 \\ \mathrm{C} & -5.9241983007 & -0.360372962 & 0.6964383765 \\ \mathrm{C} & -3.8782392042 & -0.4539926817 & -0.5995755525 \\ \mathrm{C} & -4.3640401729 & 1.4912076148 & 0.7982131019 \\ \mathrm{C} & -5.5657316483 & 0.8983293658 & 1.1931182759 \\ \mathrm{C} & -5.0845209247 & -1.0335086705 & -0.1985542409 \\ \mathrm{H} & -3.2163163726 & -0.9633560843 & -1.2928514645 \\ \mathrm{H} & -4.0778835692 & 2.4707332922 & 1.1693653219 \\ \mathrm{H} & -6.221579121 & 1.4208598357 & 1.8844936651 \\ \mathrm{H} & -5.3671946887 & -2.0087481108 & -0.5860970773 \\ \mathrm{H} & -6.8610881411 & -0.81667124 & 1.0060777619\end{array}$

\section{cocyclopentadieneIsoB}

$\begin{array}{lllc}\mathrm{C} & -0.817835732 & 1.1999673186 & 0.854915657 \\ \mathrm{H} & -1.307609544 & 1.8054430018 & 1.6277231262 \\ \mathrm{C} & -0.6403194225 & -0.2452232121 & 1.1972865127 \\ \mathrm{H} & -1.4402752005 & -0.9071244737 & 1.5037481345 \\ \mathrm{C} & 0.6481296806 & -0.5839768608 & 0.9702673327 \\ \mathrm{C} & 1.4079009855 & 0.6066574645 & 0.5049037715 \\ \mathrm{C} & 0.5474007629 & 1.6572112556 & 0.4548374025 \\ \mathrm{H} & 0.7871922668 & 2.6772854552 & 0.1833267168 \\ \mathrm{C} & 1.1630397666 & -1.9787545337 & 1.1184966517 \\ \mathrm{O} & 1.1969627467 & -2.5550491585 & 2.1906833005 \\ \mathrm{O} & 1.590644575 & -2.620600745 & 0.0136230788 \\ \mathrm{C} & 1.4109815273 & -2.0341758065 & -1.3240405254 \\ \mathrm{H} & 0.4075576567 & -1.6024997148 & -1.3870496875 \\ \mathrm{H} & 2.1550145751 & -1.2422210085 & -1.4496508462 \\ \mathrm{C} & 1.6093870997 & -3.1479066473 & -2.3335182443 \\ \mathrm{H} & 0.8654525456 & -3.9402533054 & -2.1926762517 \\ \mathrm{H} & 2.6133125785 & -3.5787737182 & -2.2461497873 \\ \mathrm{H} & 1.4937637294 & -2.7335086621 & -3.3422996283 \\ \mathrm{~S} & -1.9548255467 & 1.3879949531 & -0.6118683945 \\ \mathrm{O} & -2.1381466732 & 2.8190362768 & -0.8166374858 \\ \mathrm{O} & -1.4510158986 & 0.570162897 & -1.7062856779 \\ \mathrm{C} & 2.8422878467 & 0.637842191 & 0.1932332393 \\ \mathrm{C} & 5.5903366071 & 0.723777242 & -0.418789589 \\ \mathrm{C} & 3.3284683387 & 1.5001378489 & -0.8094743145 \\ \mathrm{C} & 3.7566260845 & -0.1795854036 & 0.8836248583 \\ \mathrm{C} & 5.1190457712 & -0.1349820628 & 0.5797598534 \\ \mathrm{C} & 4.6893842745 & 1.5432254007 & -1.1109148651 \\ \mathrm{H} & 2.6264181165 & 2.1178259927 & -1.3637319812 \\ \mathrm{H} & 3.4084141232 & -0.8354956529 & 1.6763874182 \\ \mathrm{H} & 5.8122448403 & -0.7699848317 & 1.126084479 \\ \mathrm{H} & 5.0474344756 & 2.2080684908 & -1.8934303926 \\ \mathrm{H} & 6.650420568 & 0.7528628643 & -0.658902312 \\ \mathrm{C} & -3.4896437984 & 0.6836518401 & -0.0188885319 \\ \mathrm{C} & -5.8409190376 & -0.418877469 & 0.9555513066 \\ \mathrm{C} & -3.7914437853 & -0.6491364869 & -0.3173907896 \\ & & & \end{array}$




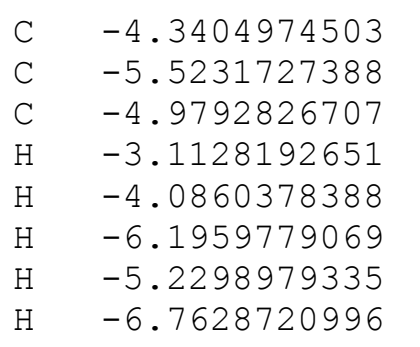

0.7614431197

1.2484630969

0.912585328

$-1.1966520745$

0.1734069472

$-0.92440949$

0.9744571092

1.8525703858

$-0.0553845344$

1.3366348305

\section{cocyclopentadieneIsoC}

$\begin{array}{llcc}\mathrm{C} & 1.2155706603 & -0.7536559643 & -0.5188175257 \\ \mathrm{C} & 1.154294793 & 0.6222048546 & -0.4789237478 \\ \mathrm{C} & -0.9585277535 & -0.2591503554 & -1.0495609604 \\ \mathrm{~S} & -2.6447524957 & -0.4093493806 & -1.5029812334 \\ \mathrm{O} & -2.9332455079 & 0.5944424419 & -2.5221748391 \\ \mathrm{O} & -2.9260518219 & -1.812782398 & -1.7787780262 \\ \mathrm{C} & 2.4195019812 & -1.6100129276 & -0.3629465386 \\ \mathrm{O} & 3.5638531387 & -1.2677161375 & -0.6040549968 \\ \mathrm{O} & 2.0663275922 & -2.8514818353 & 0.0494333171 \\ \mathrm{C} & 2.1691593416 & 1.6051105601 & -0.109215141 \\ \mathrm{C} & 4.0667137953 & 3.5527586272 & 0.6347262136 \\ \mathrm{C} & 2.1873766834 & 2.8706245479 & -0.7326909829 \\ \mathrm{C} & 3.1089291481 & 1.3433483782 & 0.9085450259 \\ \mathrm{C} & 4.0452415385 & 2.3076857894 & 1.2763733504 \\ \mathrm{C} & 3.1335749282 & 3.8300967643 & -0.3703723618 \\ \mathrm{H} & 1.4714473395 & 3.0921640223 & -1.5195700974 \\ \mathrm{H} & 3.0870094549 & 0.3877816181 & 1.4218433517 \\ \mathrm{H} & 4.7570194996 & 2.0907880099 & 2.0693183862 \\ \mathrm{H} & 3.1423466912 & 4.794201235 & -0.8730753458 \\ \mathrm{H} & 4.8011239375 & 4.3019573293 & 0.9204529161 \\ \mathrm{C} & -3.5158469376 & 0.0575423618 & -0.0054999187 \\ \mathrm{C} & -4.8161777027 & 0.7790900478 & 2.3414005269 \\ \mathrm{C} & -3.7035238052 & -0.9024078728 & 0.9964459005 \\ \mathrm{C} & -3.965018127 & 1.3730183066 & 0.1507089733 \\ \mathrm{C} & -4.6202614677 & 1.7291127566 & 1.3331362408 \\ \mathrm{C} & -4.3599516083 & -0.5343899537 & 2.1723280301 \\ \mathrm{H} & -3.3469777922 & -1.9181154894 & 0.8529312033 \\ \mathrm{H} & -3.811149201 & 2.0986414095 & -0.6418533134 \\ \mathrm{H} & -4.9786738687 & 2.746987226 & 1.4635111116 \\ \mathrm{H} & -4.5167418688 & -1.2723810202 & 2.9548081744 \\ \mathrm{H} & -5.3264423276 & 1.0607714791 & 3.2591440707 \\ \mathrm{C} & 3.1397187812 & -3.8280905169 & 0.243676476 \\ \mathrm{H} & 3.870350688 & -3.7144279307 & -0.5630730187 \\ \mathrm{H} & 2.6346544998 & -4.793032547 & 0.1497927735 \\ \mathrm{C} & 3.7846865652 & -3.6639535068 & 1.6124666368 \\ \mathrm{H} & 4.2760212047 & -2.6890337346 & 1.6953983744 \\ \mathrm{H} & 4.5389186536 & -4.4488933507 & 1.7493171586 \\ \mathrm{H} & 3.0347909004 & -3.7589291217 & 2.4063715997 \\ \mathrm{C} & -0.1011622544 & -1.2879341795 & -0.8526126927 \\ \mathrm{H} & -0.3331435762 & -2.3412489714 & -0.9514770793 \\ & & & \\ & & & \end{array}$




$\begin{array}{llll}\mathrm{C} & -0.2525183195 & 1.0448860276 & -0.8339019049 \\ \mathrm{H} & -0.7010324195 & 1.6487132644 & -0.0328984628 \\ \mathrm{H} & -0.2658329605 & 1.6730851367 & -1.7362996243\end{array}$

\section{cocyclopentadieneIsoD}

$\begin{array}{llcc}\mathrm{C} & 1.4511363722 & 0.6000560437 & -0.6458473065 \\ \mathrm{C} & 0.2408695154 & 1.208615836 & -0.5598627227 \\ \mathrm{H} & 0.0049845553 & 2.1089441587 & -0.0050316759 \\ \mathrm{C} & 1.3453169778 & -0.6260201719 & -1.531534191 \\ \mathrm{H} & 1.9989560137 & -0.5133383475 & -2.4092594338 \\ \mathrm{C} & -0.7101594267 & 0.451818587 & -1.3683967791 \\ \mathrm{C} & -0.1011343702 & -0.6049375511 & -1.9534388882 \\ \mathrm{H} & -0.562613935 & -1.356156525 & -2.5824993533 \\ \mathrm{~S} & -2.4360862908 & 0.8376549639 & -1.4983366907 \\ \mathrm{O} & -2.5673372847 & 2.275913011 & -1.6925309844 \\ \mathrm{O} & -3.0339959937 & -0.0775576069 & -2.4601098673 \\ \mathrm{C} & -3.0278034136 & 0.4240855193 & 0.1412572837 \\ \mathrm{C} & -3.8695724984 & -0.2471570556 & 2.6990658844 \\ \mathrm{C} & -3.2169971664 & 1.4388687124 & 1.0845111266 \\ \mathrm{C} & -3.2462125773 & -0.9227280741 & 0.4570427478 \\ \mathrm{C} & -3.6710757733 & -1.2533329546 & 1.7446282003 \\ \mathrm{C} & -3.6453091578 & 1.0938299992 & 2.3698449014 \\ \mathrm{H} & -3.0387892659 & 2.4748147406 & 0.8138977072 \\ \mathrm{H} & -3.0883123035 & -1.6933741989 & -0.29166525 \\ \mathrm{H} & -3.8479689396 & -2.2942207189 & 2.0025333462 \\ \mathrm{H} & -3.8023869848 & 1.8728253821 & 3.1113040593 \\ \mathrm{H} & -4.1999544817 & -0.5102254974 & 3.7008314859 \\ \mathrm{C} & 1.6957866395 & -1.9410583131 & -0.8365102248 \\ \mathrm{C} & 2.2984461557 & -4.367645705 & 0.4394609474 \\ \mathrm{C} & 2.6289737114 & -2.8192863682 & -1.3969482855 \\ \mathrm{C} & 1.0604511447 & -2.2853199033 & 0.3657847484 \\ \mathrm{C} & 1.3610736771 & -3.4915058301 & 1.0016429517 \\ \mathrm{C} & 2.9309240354 & -4.028877203 & -0.7605465377 \\ \mathrm{H} & 3.1248365028 & -2.5507416737 & -2.3269965392 \\ \mathrm{H} & 0.3339226468 & -1.6029416613 & 0.801722272 \\ \mathrm{H} & 0.8650856111 & -3.7482040541 & 1.9349399196 \\ \mathrm{H} & 3.6625640476 & -4.7019638168 & -1.2015483791 \\ \mathrm{H} & 2.534464445 & -5.3061508995 & 0.9354487787 \\ \mathrm{C} & 2.7221684553 & 1.0109022859 & -0.0311263656 \\ \mathrm{O} & 3.795882955 & 0.4789990858 & -0.2758543657 \\ \mathrm{O} & 2.5661890135 & 2.0399118067 & 0.8334568304 \\ \mathrm{C} & 3.7773359577 & 2.5376442253 & 1.482922332 \\ \mathrm{H} & 4.235839671 & 1.7102610213 & 2.0360202611 \\ \mathrm{H} & 4.4754424846 & 2.8652299666 & 0.7042970361 \\ \mathrm{C} & 3.3680587153 & 3.6767605886 & 2.3974992324 \\ \mathrm{H} & 2.6635448441 & 3.3301953316 & 3.1624952468 \\ \mathrm{H} & 2.9035995424 & 4.4892310046 & 1.8267107043 \\ \mathrm{H} & 4.2607911731 & 4.06958986 & 2.898799837 \\ & & & \end{array}$

cocyclopentadieneIsoE 


$\begin{array}{llll}\mathrm{H} & -2.243827926 & -0.6024493529 & 1.8412434667 \\ \mathrm{C} & -1.545285964 & -0.5336662314 & 0.9963563489 \\ \mathrm{C} & -0.1962310589 & -1.093286274 & 1.3862713439 \\ \mathrm{H} & -0.0185859551 & -2.1167890552 & 1.6893721614 \\ \mathrm{C} & 0.7089183781 & -0.0990525356 & 1.2522364946 \\ \mathrm{C} & 0.0769840767 & 1.1350581258 & 0.8011215614 \\ \mathrm{H} & 0.6047692467 & 2.0691703086 & 0.6505634326 \\ \mathrm{C} & -1.2560729836 & 0.9120739636 & 0.6343027268 \\ \mathrm{~S} & 2.4452223366 & -0.2681249254 & 1.5728897519 \\ \mathrm{O} & 2.8731232121 & 0.8809452027 & 2.3615272646 \\ \mathrm{O} & 2.6884931588 & -1.6137998973 & 2.0745691101 \\ \mathrm{C} & 3.1495929226 & -0.1271371393 & -0.0680943791 \\ \mathrm{C} & 4.1816459126 & 0.0888188875 & -2.6351769904 \\ \mathrm{C} & 3.1224917091 & -1.2446647177 & -0.9113287508 \\ \mathrm{C} & 3.6783975371 & 1.0969765255 & -0.4893177964 \\ \mathrm{C} & 4.1999856495 & 1.1976345315 & -1.7823734005 \\ \mathrm{C} & 3.6448362699 & -1.1298532504 & -2.2004981774 \\ \mathrm{H} & 2.7038375502 & -2.1838178202 & -0.5618217744 \\ \mathrm{H} & 3.6867293254 & 1.9477706933 & 0.1846573266 \\ \mathrm{H} & 4.6192760047 & 2.141497556 & -2.1209600822 \\ \mathrm{H} & 3.6335708453 & -1.9900761592 & -2.8646542192 \\ \mathrm{H} & 4.5863157393 & 0.1729127118 & -3.640695846 \\ \mathrm{C} & -2.1020609573 & -1.3814318877 & -0.1598055334 \\ \mathrm{O} & -1.9139292603 & -1.1531265432 & -1.3358006071 \\ \mathrm{O} & -2.7873910821 & -2.4296492099 & 0.3321006932 \\ \mathrm{C} & -3.2781019088 & -3.4264794409 & -0.6299146435 \\ \mathrm{H} & -4.0994253836 & -3.9140961302 & -0.0989911266 \\ \mathrm{H} & -3.6653740298 & -2.9025186505 & -1.5087499411 \\ \mathrm{C} & -2.1784300282 & -4.4110347585 & -0.9962482555 \\ \mathrm{H} & -1.7907810936 & -4.90885215 & -0.1000049215 \\ \mathrm{H} & -1.3564721329 & -3.9020347006 & -1.5102653066 \\ \mathrm{H} & -2.5915769269 & -5.1737103722 & -1.6679647817 \\ \mathrm{C} & -2.282959661 & 1.8505738693 & 0.1951306156 \\ \mathrm{C} & -4.2784104079 & 3.6616156364 & -0.6562002643 \\ \mathrm{C} & -3.6490618856 & 1.5046176058 & 0.2510845764 \\ \mathrm{C} & -1.9400612025 & 3.1273268734 & -0.3018381834 \\ \mathrm{C} & -2.924675203 & 4.0199925573 & -0.7192003774 \\ \mathrm{C} & -4.6343369624 & 2.3994656709 & -0.1700041397 \\ \mathrm{H} & -3.9457945871 & 0.5323744048 & 0.6353630017 \\ \mathrm{H} & -0.8938433595 & 3.4134067698 & -0.368894857 \\ \mathrm{H} & -2.637592189 & 4.9971061743 & -1.1007613492 \\ \mathrm{H} & -5.6812670227 & 2.1103248699 & -0.116188497 \\ \mathrm{H} & -5.0452217027 & 4.358800264 & -0.9849626752 \\ & & & \end{array}$

\section{cocyclopentadieneIsoANMe2}

$\begin{array}{ccrr}\mathrm{C} & -0.021632548 & 1.1981492701 & -0.6745899263 \\ \mathrm{H} & -0.1521089561 & 2.2741679885 & -0.6604768758 \\ \mathrm{C} & -0.9779746299 & 0.2885499639 & -0.9687361985 \\ \mathrm{C} & 1.0021694005 & -0.8510273213 & -0.4637027261\end{array}$




\begin{tabular}{|c|c|c|c|}
\hline & 1.2252575775 & 0.5080709102 & -0.32983992 \\
\hline & -0.4368419355 & -1.1008860209 & -0.8427769279 \\
\hline & -0.532692406 & -1.6720042436 & -1.7770095849 \\
\hline & -0.9665789673 & -1.6822222925 & -0.0733928848 \\
\hline & -2.6392783975 & 0.6720583433 & -1.4017904163 \\
\hline & -2.7538645472 & 2.1175728176 & -1.551717263 \\
\hline & -3.0322004987 & -0.1956866671 & -2.5064632801 \\
\hline & -3.5626252415 & 0.1764334844 & 0.0534 \\
\hline & -4.9442926567 & -0.5986646228 & 7832147 \\
\hline & -3.6487593796 & 1.0613931404 & 1.1350471279 \\
\hline & -4.15244 & -1.0911821462 & 3301135 \\
\hline & -4.8481982139 & -1.4741391918 & 1.2475458294 \\
\hline & -4.34700 & 0.6669314151 & 2.27 \\
\hline & -3.182859014 & 2.0406900165 & 1.0780484645 \\
\hline & -4.0729346355 & -1.758954463 & -0.7547776271 \\
\hline & -5.3149424192 & -2.4547545266 & 1.2918790708 \\
\hline & -4.4258322475 & 1.347087015 & 3.1220047249 \\
\hline & -5.4859897462 & -0.9014562303 & 3.2274354523 \\
\hline & 2.391032754 & 1.2451847689 & 0.1460864103 \\
\hline & 4.652512415 & 2.7395603182 & 1.0795262562 \\
\hline & 3.2500241411 & 0.7353249459 & 1.1410670437 \\
\hline & 2.6706105839 & 2.5404108622 & -0.338961851 \\
\hline & 3.7684883256 & 3.2683490625 & 0.0981540646 \\
\hline & 4.3416073481 & 1.4519694295 & 1.603954818 \\
\hline & 3.0416739421 & -0.2362092702 & 1.5763760786 \\
\hline & 2.0245363341 & 2.9793218547 & -1.09568586 \\
\hline & 3.942063868 & 4.2523567123 & -0.3224236555 \\
\hline & 4.9529429312 & 1.0193216999 & 2.3879821551 \\
\hline & 1.9065958129 & -2.000249547 & -0.3492489264 \\
\hline & 1.5148906905 & -3.1417968041 & -0.1287835463 \\
\hline & 3956644 & -1.6830973684 & -0.5800247031 \\
\hline & 031 & -2.7334513174 & -0.40 \\
\hline & 3.811762756 & -3.6722794805 & -0.8065902749 \\
\hline & 5.0479748102 & -2.3973850211 & -1.0062509138 \\
\hline & 4.5883229966 & -2.8763923004 & 1.0655093529 \\
\hline & 3.7252830087 & -3.1866377701 & 1.6642655463 \\
\hline & 4.9749314615 & -1.9288666551 & 1.4570394367 \\
\hline & 5.3706569444 & -3.6401139703 & 1.1587674959 \\
\hline & 5.7480250211 & 3.4412959894 & 1.5101844949 \\
\hline & 6.587496213 & 2.9068663577 & 2.577718018 \\
\hline & 6.9791486271 & 1.9175246903 & 2.3054694139 \\
\hline & 6.0274546858 & 2.8036507786 & 3.5202578987 \\
\hline & 7.430805803 & 3.5807869776 & 2.7408543834 \\
\hline & 5.9754849685 & 4.8036853997 & 1.038706549 \\
\hline & 5.1474463513 & 5.4717566102 & 1.3217888381 \\
\hline & 6.0709509495 & 4.8267388463 & -0.0555491522 \\
\hline & 6.9 & 5.1841375619 & 1.4758702535 \\
\hline
\end{tabular}

\section{cocyclopentadieneIsoCNMe2}

C $\quad 1.3064133856 \quad-0.716942983 \quad-0.4227552756$ 


\begin{tabular}{|c|c|}
\hline & 1.2650534629 \\
\hline & -0.850829177 \\
\hline & -2.5199660848 \\
\hline & -2.7937100148 \\
\hline & -2.8105638651 \\
\hline & 2.4813007162 \\
\hline & 3.6460088979 \\
\hline & 2.0916579445 \\
\hline & 2.2535331516 \\
\hline & 4.1458039501 \\
\hline & 2.1737649197 \\
\hline & 3.2942601853 \\
\hline & 4.2042976646 \\
\hline & 3.0873470717 \\
\hline & 1.3878636433 \\
\hline & 3.368476268 \\
\hline & 4.9643472817 \\
\hline & 2.9870963497 \\
\hline & -3.423580876 \\
\hline & -4.7642520237 \\
\hline & -3.6455475778 \\
\hline & -3.8596577622 \\
\hline & -4.534490118 \\
\hline & -4.3218259541 \\
\hline & -3.2991402875 \\
\hline & -3.6805761122 \\
\hline & -4.8817870026 \\
\hline & -4.5045844921 \\
\hline & -5.2897937381 \\
\hline & 3.1358784258 \\
\hline & 3.8852009975 \\
\hline & 2.6119182757 \\
\hline & 3.7619573032 \\
\hline & 4.2760471524 \\
\hline & 4.4934867635 \\
\hline & 2.9960874862 \\
\hline & -0.008120175 \\
\hline & -0.253329204 \\
\hline & -0.1339394316 \\
\hline & -0.5951637604 \\
\hline & -0.1220804614 \\
\hline & 5.0593912408 \\
\hline & 6.1193922921 \\
\hline & 5.7035396317 \\
\hline & 6.7608258345 \\
\hline & 6.7315334446 \\
\hline & 4.9449931133 \\
\hline & 4.9853872049 \\
\hline & 5.7721864771 \\
\hline & 3.9967475824 \\
\hline
\end{tabular}

$\begin{array}{cc}0.6743419597 & -0.4248519261 \\ -0.2072951632 & -1.0244163773 \\ -0.3530230586 & -1.5062080379 \\ 0.6456771753 & -2.5363762331 \\ -1.7567993264 & -1.7771789264 \\ -1.5991776873 & -0.260481239 \\ -1.2872029254 & -0.4555529861 \\ -2.8553670853 & 0.0911139165 \\ 1.6591495734 & -0.0525570971 \\ 3.6807201766 & 0.7126417968 \\ 2.9829013284 & -0.5510075792 \\ 1.3923698487 & 0.8688110035 \\ 2.3615776628 & 1.2498284531 \\ 3.9615146951 & -0.1982184496 \\ 3.2436058389 & -1.2548052726 \\ 0.4092363541 & 1.3185289635 \\ 2.1029251257 & 1.978408683 \\ 4.9500080569 & -0.6319694861 \\ 0.1276625874 & -0.029538069 \\ 0.8728327047 & 2.2897278653 \\ -0.8261541737 & 0.9714446001 \\ 1.448896133 & 0.115436798 \\ 1.8170771737 & 1.2833055749 \\ -0.446928352 & 2.1324578387 \\ -1.8467921808 & 0.838244437 \\ 2.1704350001 & -0.6755843944 \\ 2.8401285067 & 1.4036820206 \\ -1.1811581018 & 2.9129461587 \\ 1.1635245514 & 3.1960212706 \\ -3.8638714321 & 0.2511588507 \\ -3.7287876799 & -0.5351872771 \\ -4.8116128934 & 0.0989205868 \\ -3.7901221284 & 1.6372619492 \\ -2.8339429797 & 1.7795338805 \\ -4.6008385095 & 1.7452903815 \\ -3.9062380936 & 2.4130795132 \\ -1.237009415 & -0.7668455134 \\ -2.2896065168 & -0.837671093 \\ 1.0965807703 & -0.8369504225 \\ 1.7315761807 & -0.0688193899 \\ 1.6898635285 & -1.7622666166 \\ 4.6346330932 & 1.0616247454 \\ 4.3240732855 & 2.0173184177 \\ 4.052323797 & 2.9987581646 \\ 5.1989756973 & 2.1371464033 \\ 3.4835523505 & 1.6624358819 \\ 5.9908507998 & 0.5319468782 \\ 5.9867692216 & -0.5662710331 \\ 6.5942260606 & 0.9100448352 \\ 6.4577614479 & 0.8361928263 \\ & \end{array}$

$0.6743419597 \quad-0.4248519261$

$-0.2072951632-1.0244163773$

$0.6456771753-2.5363762331$

$-1.7567993264 \quad-1.7771789264$

$-1.5991776873-0.260481239$

$-1.2872029254-0.4555529861$

$\begin{array}{ll}-2.8553670853 & 0.0911139165\end{array}$

$1.6591495734 \quad-0.0525570971$

$3.6807201766 \quad 0.7126417968$

$2.9829013284 \quad-0.5510075792$

$3.9615146951-0.1982184496$

$3.2436058389-1.2548052726$

$0.4092363541 \quad 1.3185289635$

$2.1029251257 \quad 1.978408683$

$4.9500080569-0.6319694861$

$0.1276625874-0.029538069$

$0.8728327047 \quad 2.2897278653$

$-0.8261541737 \quad 0.9714446001$

$8170771737-1.2833055749$

$\begin{array}{ll}-0.446928352 & 2.1324578387\end{array}$

$\begin{array}{ll}-1.8467921808 & 0.838244437\end{array}$

$2.1704350001-0.6755843944$

$2.8401285067 \quad 1.4036820206$

$-1.1811581018 \quad 2.9129461587$

$1.1635245514 \quad 3.1960212706$

$\begin{array}{ll}-3.8638714321 & 0.2511588507\end{array}$

$-3.7287876799-0.5351872771$

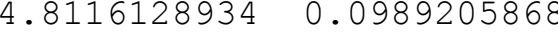

$\begin{array}{ll}-3.7901221284 & 1.6372619492\end{array}$

$-4.6008385095 \quad 1.7452903815$

$-3.9062380936 \quad 2.4130795132$

$-1.237009415 \quad-0.7668455134$

$-2.2896065168 \quad-0.837671093$

$1.7315761807 \quad-0.0688193899$

$1.6898635285-1.7622666166$

$4.6346330932 \quad 1.0616247454$

$.3240732855 \quad 2.0173184177$

$.052323797 \quad 2.9987581646$

$5.1989756973 \quad 2.1371464033$

$3.4835523505 \quad 1.6624358819$

$5.9908507998 \quad 0.5319468782$

$5.9867692216-0.5662710331$

$6.4577614479 \quad 0.8361928263$ 